\title{
Habitus: supervisión de la calidad asistencial desde la perspectiva doméstica de la atención
}

\section{Alejandro Gómez Ordoki}

ago2804@gmail.com
Adinekoentzako egoitza-zentroen ikuskapen publikoa ex ante ereduetan oinarrituta zabaltzen da (dagozkien arautegien eskakizun materialekin eta funtzionalekin zuzenean lotuta), edo ex post sistemetan oinarrituta (emaitzen gaineko ebaluazioprozesuak). Bi eredu horiek arretaren kalitatea "ikuspegi ofizialetatik" agerian jartzera bideratutako deskriptoreak identifikatzen dituzte. Ikuspegi ofizial horiek, funtsean, araua betetzean oinarritzen dira, eta, herrialde berritzaileenetan, pertsona ardatz duen arretari erreferentzia egiten dioten adierazleekin batera ager litezke. Hala ere, litekeena da jardunbide egokien kontzeptualizazio publikoa bat ez etortzea etxekotasun-giroak blaitutako egoitza-arreta helburu duen ingurune soziofamiliar baten sentsibilitatearekin. Dena dela, asmo hori etenda gera liteke arretaren ikuspegi domestiko hori behar bezala sistematizatuta, objetibatuta eta ebaluatuta ez badago. Eredu teoriko honen bidez, helburu hori betetzen dela bermatu nahi da, kalitatezko arretaren zerbitzura dauden kudeaketatresnen berezko zorroztasuna oinarri hartuta.

\section{GAKO-HITZAK:}

Gainbegiratzea, etxeko ikuspegia, ongizatea, etxekotzea, enpatia, pertsona ardatz duen arreta, partaidetza soziofamiliarra.
La inspección pública de centros residenciales para personas mayores se despliega desde modelos ex ante (directamente relacionados con las exigencias materiales y funcionales de las correspondientes normativas reguladoras) o desde sistemas ex post (procesos evaluativos sobre resultados). Ambos modelos identifican descriptores fundamentalmente orientados a evidenciar la calidad de la atención desde "perspectivas oficiales", básicamente soportadas en la observación de la norma y que, en los países más innovadores, podrían venir acompañadas de indicadores referenciados en la atención centrada en la persona. No obstante, la conceptualización pública de las buenas praxis podría no ser compartida desde la sensibilidad de un entorno sociofamiliar que aspira a que la sensación de hogar impregne la atención residencial. Este ánimo podría verse truncado si la perspectiva doméstica de la atención no está sistematizada, objetivada y evaluada. El presente modelo teórico pretende garantizar el cumplimiento de este anhelo desde el rigor propio de las herramientas de gestión al servicio de una atención de calidad.

\section{Palabras clave:}

Supervisión, perspectiva doméstica, bienestar, hogarización, empatía, atención centrada en la persona, participación sociofamiliar. 


\section{Una evolución imparable: de la institucionalización (beneficencia) a la hogarización (ACP)}

La evolución experimentada por los servicios residenciales para personas mayores en las últimas décadas ha permitido el desarrollo de modelos de atención que han corregido con éxito muchos de los déficits que presentaba la beneficencia, obsoleta en su aplicabilidad desde el mismo instante en el que la contraprestación económica por la prestación de un servicio (precio) es consecuencia teórica del nivel y las condiciones en las que este debe ser prestado (norma). Las Administraciones Públicas asumen por ley la responsabilidad de atender a los más desfavorecidos y comienzan a legislar en consecuencia. Son los primeros pasos de una consolidación progresiva del sector que acentúa la profesionalización, que avala la sistemática de atención conforme a normas internacionalmente aceptadas (gestión de calidad por procesos), que contrasta la recogida de la información y agiliza su explotación (TIC, intranet y/o extranet) y que, finalmente, somete el cumplimiento de cuantas obligaciones sean efectivas desde mecanismos de control exhaustivos y periódicos (inspecciones públicas). El sector público amplía su red residencial concertada y va incorporando nuevos elementos de control para garantizar la trazabilidad en cuantos circuitos intervienen en la atención integral a las personas mayores en residencias. Poco a poco, la pretendida inercia de mejora se transforma en una especie de espiral convulsa que solo acepta el trinomio norma-control-dato como única perspectiva válida para evaluar la calidad de atención en los centros. Una atención, por otra parte, muy protocolizada, asentada sobre tareas asistenciales programadas en horarios fijos y desarrollada desde procedimientos uniformes. La historia y modo de vida de las personas residentes, sus ritmos y preferencias, quedan en un segundo plano y, en consecuencia, no forman parte de una consciencia asistencial fundamentalmente centrada en la enfermedad y no en las capacidades potenciales de cada individuo. Esta perspectiva podría llegar a afectar negativamente al bienestar psicoemocional de las personas usuarias en la medida que se limitan sus capacidades para tomar decisiones y poder seguir viviendo conforme a sus hábitos y preferencias. Los criterios técnicos y organizativos, dictados desde los órganos directivos de los centros residenciales, prevalecen sobre aquellos otros derivados de perspectivas que defienden la prestación del servicio desde nuevos parámetros (respeto de las preferencias y deseos como parte de una historia de vida sobre la que soportar un plan de atención personalizado, además de individualizado).

Desde las corrientes de pensamiento derivadas de la psicología humanista, comienzan a tomar cuerpo otras alternativas asistenciales más próximas a considerar al individuo como un ser único e irrepetible y que, en consecuencia, debe será atendido conforme a su centralidad, en un intento practicable de que la organización se adapte a la persona y no la persona a la organización. El panorama asistencial comienza a ser consciente de la existencia de la atención centrada en la persona (ACP) y a considerar otras soluciones residenciales (housing, unidad de convivencia, etc.) como alternativas válidas para dar respuesta a un nuevo paradigma asistencial caracterizado por demandar servicios desde nuevos parámetros: individualidad, historia y proyecto de vida y libre elección. El futuro, sin lugar a dudas, es absolutamente atractivo para consolidar lo esencial del modelo actual y avanzar en el diseño de nuevos métodos que propicien el tránsito natural de "mi casa" a "mi nuevo hogar", en términos de mudanza voluntaria y no de institucionalización. La oferta asistencial deberá garantizar, desde el ejercicio de los derechos fundamentales de las personas residentes y el cumplimiento de los derechos laborales de las y los profesionales del sector, los siguientes principios asistenciales: suficiente calidad asistencial, buen trato -en términos de respeto y delicadeza por parte del personal-, continuidad de los cuidados y equilibrio sostenible entre planteamientos excesivamente polarizados (respuesta a las necesidades de cada persona u oferta asistencial basada en los intereses colectivos). En el cumplimiento de estos principios se abrirá un nuevo panorama de interactuación en el que todos los entes implicados (Administraciones Públicas, organizaciones gestoras de servicios, personas usuarias, entornos sociofamiliares y sindicatos) deberían ser capaces de reflexionar sobre la idoneidad de la atención centrada en la persona. Porque todos y todas seremos mayores $y$, en base a este futurible, deberíamos apostar por unidades residenciales basadas en la calidad de vida, en la calidad del servicio (complementariedad ISO-ACP) y en la calidez de trato que, en nuestra condición de seres humanos, todos deseamos.

La división tradicional de la atención residencial (la tríada actividades de la vida diaria-sanidadpsicosocial) debería adaptarse a una nueva perspectiva que busca ansiosamente la individualidad de la persona hasta identificarla como un sujeto único y singular. Si lo que se pretende es traer "mi hogar" a la residencia, la persona residente y su entorno sociofamiliar más íntimo deberían sentir el geriátrico como "su casa”. En ese empeño, los modelos de atención centrada en la persona son buenísimos canalizadores. Esta pretensión, sin embargo, podría chocar frontalmente con una dinámica imparable de residencias que, abandonando los postulados de atención propuesto por la beneficencia, han ido profesionalizando sus organizaciones como consecuencia de los requisitos públicos para la acreditación y/o concertación de plazas. De alguna manera, hemos ido pasando de la beneficencia a la "beneficiencia" apoyados, también, en las posibilidades que ofrecen las nuevas tecnologías de la información. Con el nuevo escenario, derivado de la implantación casi ilimitada de sistemas de gestión de calidad, hemos descrito 


\begin{tabular}{|l|}
\hline Principios facilitadores \\
\hline - La estancia en una residencia para personas mayores debe \\
vivirse como una proyección natural del domicilio abandonado \\
(“me cambio de casa" y no "voy a una residencia”). \\
- La participación del entorno sociofamiliar más íntimo de la \\
persona residente debe ser una opción real y flexible, y no \\
una aspiración a la que nunca llegamos porque la sometemos \\
a todos tipo de limitaciones que dificultan o imposibilitan su \\
ejercicio práctico.
\end{tabular}

Fuente: Elaboración propia.

toda una suerte de indicadores "muy centrados en objetivos clínico/terapéuticos o en objetivos de una buena gestión económica" (Martínez Rodríguez, 2017). Pero la inercia que la ACP propone es la de iniciar un análisis introspectivo para la definición de indicadores relativos a términos como "autonomía", "bienestar", "armonía", "satisfacción", "disfrute", "serenidad" o "desarrollo personal", sin que, por ello, se abandonen los beneficios derivados de la medición de determinados indicadores "tradicionales". En definitiva, debería empezar a tomar cuerpo todo aquello que nos ayude a "evidenciar" la felicidad de nuestras y nuestros mayores en centros residenciales.

\section{La perspectiva doméstica de la atención en los 'softwares' especializados en gestión residencial}

Muchos de los softwares generalistas de gestión de centros residenciales para personas mayores han ido evolucionando progresivamente en la generación de diferentes módulos para las distintas áreas de gestión. Así, han incorporado paulatinamente diferentes interfaces en función de las demandas de sus clientes que, a su vez, ha identificado nuevos módulos desde las necesidades diarias de gestión (endógenas o propias de cada organización) o desde los requisitos públicos en aplicación de las normas vigentes (exógenos o requeridos para dar respuesta a las inspecciones oficiales). En una dinámica tan dependiente de la eficacia en la gestión medida desde parámetros normativos de cualquier índole, el desarrollo de módulos que den respuesta al registro y explotación de datos en los ámbitos de cuidados de la salud, atención para las actividades de la vida diaria y gestión de recursos humanos - por citar, quizás, los más relevantes- es prácticamente troncal a todos los softwares que procura el mercado, porque, precisamente, se constituyen en el abecé de la prestación de servicios residenciales a personas mayores con dependencia.

No obstante, y a pesar de su evidente transcendencia asistencial, el registro de datos correspondientes a la evaluación sistematizada de la calidad prestada en la ejecución de aquellos trabajos o tareas directamente relacionados con la labor profesional de quienes se perfilan como el eje vertebrador de la atención -personal gerocultor-, no forma parte

\section{Principal obstáculo externo}

- Inspecciones excesivamente garantistas que parecen querer buscar casi exclusivamente el incumplimiento de la norma y, así, constituirse en garantía de defensa ante posibles denuncias por supuestas negligencias. ¿Una norma exhaustiva no podría pervertir nuestra percepción y convertirnos más en burócratas que en personas que cuidan de personas? de ninguno de los módulos de los softwares con mayor implantación. Por ello, dada la importancia de garantizar la ejecución de las tareas conforme a unos estándares de calidad generalmente aceptados, el diseño de herramientas que posibiliten el registro, análisis y explotación de datos relacionados con las buenas praxis debería ser algo consustancial a cualquier software especializado en la gestión de centros residenciales. Sin embargo, la revisión del contenido de los distintos softwares concluye en un mismo punto: ninguno de ellos plantea, en grado alguno, la supervisión del trabajo como una herramienta necesaria para el contraste de la calidad de los servicios prestados desde la percepción y sensibilidad del entorno sociofamiliar. Esta pretendida perspectiva doméstica de la atención, especialmente importante en caso de residentes con deterioro cognitivo grave, no debería ser confundida en medida alguna con ninguna de las encuestas de satisfacción al uso ni, asimismo, debería ser utilizada como sustitutiva de ellas. Al contrario, ambas herramientas se complementarían en una asociación perfecta, en una relación de causaefecto que avalaría los resultados obtenidos en la medición de la satisfacción del cliente cualquiera que fuera el mismo (residente, entorno sociofamiliar o Administración Pública). Un sistema de evaluación continua como el desarrollado tiene carácter preventivo y, en consecuencia, su validez debería ser refrendada por la obtención de buenas puntuaciones en el nivel de satisfacción (encuestas).

\section{Principios del método}

Evidentemente, tal y como ocurre en cualquier empresa de producción de bienes o servicios, no podríamos supervisar todos y cada uno de los trabajos/tareas pautados para un día de atención ni, en menor medida aún, garantizar que dicha supervisión se haga para la totalidad de la población atendida en cada centro residencial. Asoma, en consecuencia, la idea de trabajar con muestras aleatorias estadísticamente significativas que ayuden a componer el plano simétrico del conjunto de tareas de atención directa y que, en un geriátrico, no es otro que el control de calidad de dichas tareas. Si desde las correspondientes normativas cuantificamos las horas anuales/diarias que cada comunidad autónoma propone como mínimamente necesarias para cubrir la ayuda de tercera persona 
para la realización de las AVD en función del perfil de dependencia o, en su caso, otras referencias como las propuestas desde métodos alternativos como DENAdat (Auren, 2019), para comprobar que la prestación del servicio se ajusta a unos niveles de calidad dentro de los estándares definidos, deberíamos contar con un método sistematizado de supervisión. Como para cualquier otro proceso de implantación de una metodología de trabajo, el entramado teórico que se diseñe debería ser refrendado por la realidad en una dinámica propia de la sistemática PDCA o de Deming ("plan-do-checkact”, esto es, "planificar-hacer-verificar-actuar"). Nuestro modelo no aspira a ser menos y en esa correspondencia, desde la observación y análisis de los datos, impulsa una dinámica recurrente en el tiempo para ir ajustando el método de supervisión por efecto de la propia experiencia adquirida.

Como personas que cuidamos de personas, factores de muy diversa índole nos condicionan diariamente y, asimismo, dificultan que los servicios prestados se sucedan conforme a un patrón asistencial y temporal constantes (por ejemplo, la improbabilidad de que todos los días se consuma un mismo tiempo de personal gerocultor en ejecutar una misma tarea). En nuestro sector, la presencia de factores intangibles supedita la producción de servicios al grado en que se presenten, una posibilidad que, por otra parte, se reproduce en condición de aleatoriedad. La ayuda de tercera persona en función del nivel de dependencia debe expresarse en términos de actos necesarios a realizar por el personal gerocultor para que la persona residente pueda tener cubiertas sus necesidades de la vida diaria. Nuestro output es ayudar, con una determinada intensidad, con una disponibilidad personalizada, siendo además eficientes. Dicho de otra manera, deberemos organizar el trabajo del personal gerocultor de tal modo que se conjuguen intensidades máximas (ayuda total o completa) y mínimas (supervisión), que garanticen una correcta y suficiente calidad en la prestación del servicio con un número adecuado de auxiliares de geriatría. La cuestión, en todo caso, es definir lo que entenderemos como "calidad estándar", no como un concepto definido desde la perspectiva pública sino desde la sensibilidad del entorno sociofamiliar. La definición de estándares es especialmente importante porque en caso contrario cada organización interpretaría la prestación del servicio de manera particular. En consecuencia, cualquier pretensión encaminada a comparar la calidad asistencial sin referenciar la comparativa desde un marco común valdría lo mismo que la fijación de un precio público independientemente del valor de las ratios de atención: nada. Surge, por tanto, la necesidad de diseñar una herramienta que permita estandarizar la calidad de dicho servicio de acuerdo a criterios objetivos, generales y acordes a lo que el entorno sociofamiliar interpreta como esencial en la atención. Los resultados obtenidos en determinadas supervisiones clave nos aproximarán fielmente al nivel de calidad percibido como estándar. En esta línea de interpretación se alinea el modelo desarrollado, un sistema de supervisión flexible que actúa sobre aquellas áreas de atención que cada organización determine de "impacto" para la evaluación de la calidad del servicio prestado. Indudablemente, estas áreas deberían responder de las expectativas de los principales actores en la percepción de la calidad prestada: personas residentes y/o entorno sociofamiliar, Administración Pública acreditadora y/o concertadora de plazas y profesionales del centro.

\subsection{Indicadores propios de una perspectiva doméstica y su relación con modelos ACP}

Para evidenciar la calidad es indispensable contar con una buena batería de indicadores. Pero no cualquier indicador es válido para este propósito. El diseño de un monitor de indicadores consensuado es necesario para permitir dinámicas de benchmarking. Un buen set de indicadores de evaluación debería combinar la verticalidad de los indicadores de proceso (sanitario, psicológico, AVD y social) con la transversalidad del modelo de calidad de vida y la atención centrada en la persona. La validez del panel de indicadores resultante vendría determinada por el contraste/valoración de las opiniones de las personas residentes y/o su entorno familiar, los centros gestores y la inspección pública. A su vez, dicho panel debería servir para conceptualizar el sentido integral de la atención residencial a personas mayores como aquellos procesos garantistas de buenas praxis adaptados a la centralidad de la persona para conseguir la mayor calidad de vida posible.

El paradigma de atención fundamentado en la centralidad de la persona requiere un avance gradual en la definición de indicadores que complementen, desde la perspectiva de la ACP, la composición tradicional de cuadros de mando sesgados hacia lo clínico y/o económico. En no pocas ocasiones, la defensa a ultranza de métodos de evaluación soportados sobre las bondades de la eficiencia económica supedita la atención residencial a perspectivas que basan el avance casi exclusivamente en la aplicación de las nuevas tecnologías de cualquier índole (pantallas táctiles para el registro de incidencias varias, tablets, elementos mecánicos de desplazamiento, domótica y/o robótica aplicada en entornos geriátricos, etc.). Así como la progresiva implantación de la tecnología necesaria debe ser parte irrenunciable de la planificación estratégica de las organizaciones -si la racionalidad pondera su presencia-, también una dinámica de continuo análisis introspectivo para la definición de indicadores relativos al estado psicoemocional debería constituirse en eje estratégico. En esta línea de actuación, deberíamos ser capaces de evaluar conceptos asistenciales más ligados a la qualis (cualidad, en el sentido de dimensionar lo que Martin Knapp (2018) identifica como factores intangibles de la atención) que a la quantitas (en palabras del propio Knapp, 
factores tangibles en la producción de servicios). En definitiva, se propone un cambio de enfoque para alinear la evaluación de los servicios también con todo aquello que nos ayude a conseguir la felicidad para nuestras y nuestros mayores. Y, para la consecución de este objetivo, la formación en ACP debería constituirse en un aliado irrenunciable para que esta filosofía asistencial inunde todas las áreas de las organizaciones. Únicamente desde un enfoque participativo que fluya de abajo hacia arriba impregnaremos, casi por capilaridad, las sensibilidades de todos los agentes que interactúan en la realidad cotidiana de los centros residenciales: residentes, entorno sociofamiliar y profesionales. Para ello también es necesario que la dirección del centro esté convencida de las bondades del modelo y demuestre su implicación desde su proyección a todos los rincones de la organización.

Las diferentes normativas reguladoras de la atención a personas mayores en centros residenciales definen el marco de actuación en cada comunidad autónoma. Se constata que ni los requisitos funcionales ni los materiales son equiparables entre las distintas autonomías del Estado. A pesar de ello - con independencia de ello, diríamosdebería garantizarse la individualidad de cada persona dentro del referido marco, aun cuando el mapa estatal de precios, costes y ratios de atención es ciertamente disperso. Las medidas para garantizar el respeto a la dignidad de cada persona deberían transcender estas comparativas y constituirse en instrumentos de aplicación universal; deberían hacerlo, al menos, desde el compromiso del cumplimiento de ciertos mínimos. Podríamos sintetizar la ACP como aquella filosofía de atención garante de la centralidad de la persona independientemente del marco. La atención centrada en la persona, implementada desde distintos despliegues procedimentales según las referencias bibliográficas consultadas, no es sistemáticamente asimilable a un modelo de gestión de calidad. $\mathrm{Si}$ estos últimos se corresponden con el ciclo PDCA y buscan la eficiencia desde procesos de mejora continua con resultados objetivamente medibles, la ACP trata del "reconocimiento de la dignidad de cada persona y de su derecho a seguir siendo dueña de su vida" (Martínez Rodríguez, 2017). Son dos vectores que aparentemente imprimen fuerza en sentido contrario pero que deberían ser planteados desde los beneficios alcanzables si convivieran en clave simbiótica.

Evaluar un centro desde la cuantificación de indicadores descriptivos como, por ejemplo, la tasa de diabéticos o el número de caídas, no parece un método especialmente adecuado para concretar hasta qué punto la atención se presta en perspectiva personalizada. La evaluación debe "tocar" la dimensión humana de la atención y relativizar la incuestionable importancia de otras descriptivas que, desde la perspectiva doméstica de la atención, no aportan valor cualitativo a la evaluación de los servicios. Dicho de otro modo, dado que no podemos contemplar la negligencia como algo recurrente en el tratamiento de la salud o de cualquier otro ámbito asistencial, los nuevos sistemas de evaluación deberían incidir más en la forma de la atención que en el fondo, algo que, por otra parte, es inherente al sistema residencial desde la estandarización de protocolos, procesos, tareas y funciones propios de cada categoría profesional.

Culturalmente hablando, la cuenca mediterránea, a diferencia de Centroeuropa o los países nórdicos, se constituye en baluarte de la familia como institución principal al servicio de las personas mayores. Es de esperar que en un escenario semejante se prolongue la edad media de acceso a los centros residenciales $y$, consecuentemente, las personas que acudan a ellos para ser atendidas lo hagan en circunstancias especialmente demandantes. En un contexto asistencial como el descrito, la prevalencia de estados de salud delicados se constituye en algo intrínseco al sistema y, dada esta presencia, debe ser tratada porque no se puede obviar. Si bien las Administraciones Públicas, en su condición de garantes de una mínima qualis en la atención residencial, no deben abstraerse de esta realidad, tampoco deberían centrarla como único ámbito de medición y evaluación. Ni tan siquiera en un contexto tan dramático como el recientemente vivido con la propagación de la COVID-19. Incidir en la dimensión humana de la atención, en la individualidad y excepcionalidad de cada persona, ayudará al diseño de centros tan preocupados por el bienestar psicoemocional como por el bienestar físico o la sostenibilidad económica de las organizaciones. Atender a nuestras y nuestros mayores también es asegurar la cualidad humana de la atención, probablemente única condición inalterable cualquiera que sea la perspectiva asistencial.

\section{2. ¿Qué se entiende por supervisión de la atención prestada por el personal gerocultor?}

Si realizáramos una encuesta estatal para obtener como resultado el porcentaje de centros residenciales que supervisan la atención prestada, obtendríamos un valor más que satisfactorio, probablemente cercano al cien por cien. Si extrajéramos una muestra aleatoria de centros y analizáramos en qué procesos $\mathrm{y} / \mathrm{o}$ procedimientos se soporta la afirmación, empezaríamos a cuestionarnos su validez. Con frecuencia apreciable nos encontraríamos con organizaciones que actúan de modo correctivo sobre incidentes concretos y con diferentes niveles de base documental para fijar la trazabilidad de la no conformidad. En el peor de los casos, si el hecho causante de la no conformidad no origina consecuencia grave alguna en el estado de salud de la persona residente afectada, y este no se produce en presencia de terceras personas que lo atestigüen, podría, incluso, no ser registrado. Si, por el contrario, el sondeo buscara cuantificar el número relativo de centros que, cualquiera que fuera el método de evaluación empleado, sistematizan 
la observación de las prácticas profesionales, registran los datos y toman decisiones conforme al análisis de los resultados observados, obtendríamos un valor sensiblemente inferior al obtenido en el primer escrutinio. Si, además, acompañáramos la pregunta con la disponibilidad de herramientas informáticas para el análisis y seguimiento de los datos, la respuesta reflejaría un número mínimo de centros con sistemas de información ad hoc. En consecuencia, podríamos estimar que la supervisión de tareas de personal gerocultor es un concepto manido en el discurso pero de escasísima implantación práctica.

De igual modo, desde el análisis de los diferentes módulos de formación que se ofertan en la red llegaríamos a una misma conclusión: los cursos de supervisión sociosanitaria son escasos y sus contenidos, cuando se imparten en formato de formación reglada con diferentes unidades didácticas, si bien tratan la atención desde las perspectivas tradicionales (salud y AVD) no proponen alternativas desde la percepción doméstica del entorno sociofamiliar ni desde los planteamientos asistenciales de la ACP.

Como ya se ha comentado, un modelo de evaluación basado en la extensión de la continuidad de los cuidados domiciliarios a un entorno residencial debe integrarse con la idea de "hogarización" en la atención. Las personas residentes y sus entornos más íntimos deben sentir que la residencia es su nuevo hogar. Esta sensación de atención cuasi familiar basada en la proximidad y el respeto no puede ser percibida desde unas inspecciones programadas y eminentemente dirigidas a la comprobación del cumplimiento de la norma. Aun cuando es absolutamente necesaria una nueva perspectiva evaluativa desde las Administraciones Públicas, el cambio - de producirse-conllevaría la valoración de cuantos mecanismos asistenciales deba implementar cada organización para prestar el servicio conforme a los parámetros de los modelos de calidad de vida y ACP, además de los que hacen referencia a los procesos de atención tradicionalmente considerados y que ya forman parte de los sistemas de inspección. En este sentido, los nuevos enfoques públicos en la evaluación de la atención buscarían dotarse de argumentos para acreditar que los centros cuentan con procesos y procedimientos que garantizan la prestación en clave de calidad de vida y ACP. Aunque, en la práctica, la mayoría de los marcos normativos del Estado no contemplan estos dos vectores como ejes que delimitan los modelos de atención (diecisiete años de antigüedad media en las normas y casi la mitad de ellas por encima de los quince años impiden la consideración de estas categorías de evaluación); además, cuando lo hacen, su presencia se limita a referencias vagas y en absoluto protocolizadas (valga como ejemplo el recientemente aprobado Decreto $126 / 2019$, de 30 de julio, de centros residenciales

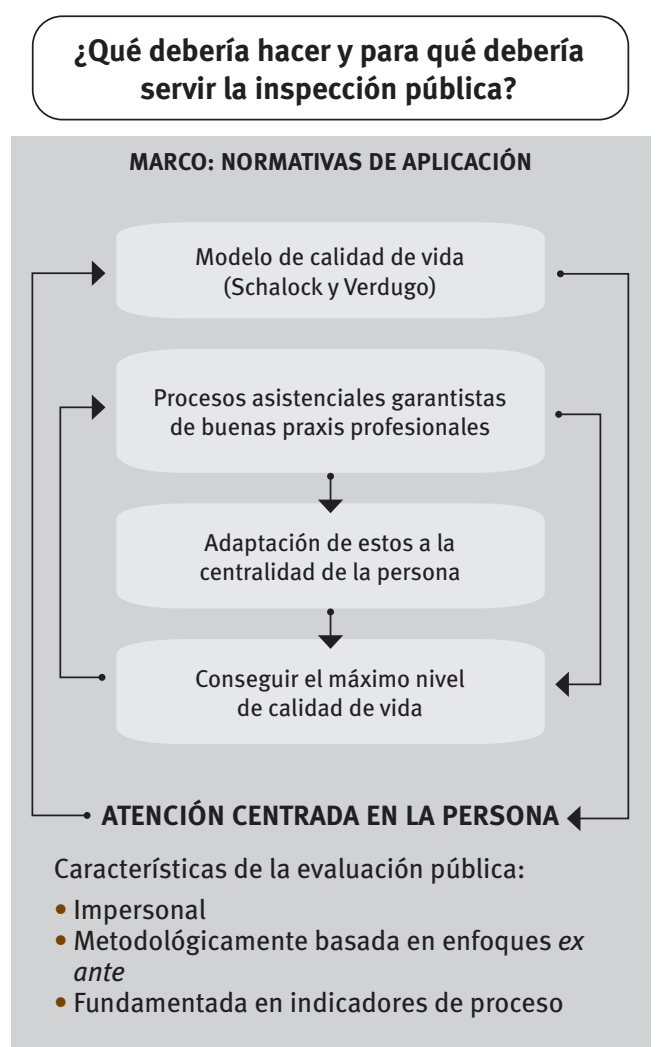

¿Qué hace y para qué sirve la evaluación desde la perspectiva doméstica?

MARCO: PERCEPCIÓN DE LA “CALIDAD” DESDE LA PERSPECTIVA DE LA PERSONA RESIDENTE Y/O SU ENTORNO FAMILIAR

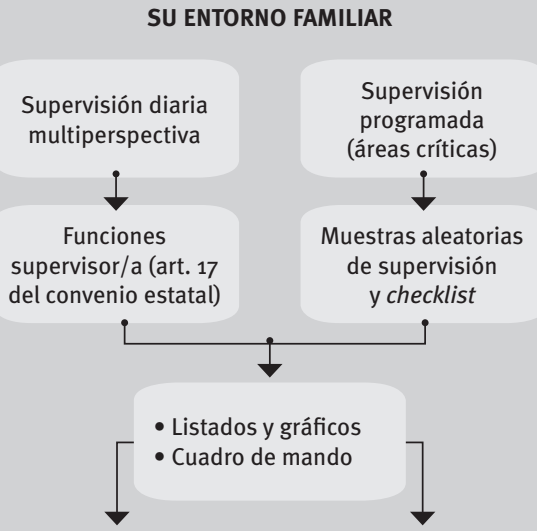

Cada centro

Redes asistenciales (perspectiva micro)

Características de la evaluación interna:

- Evaluación personalizada (residente/ trabajador/a)

- Enfoque expost

- Fundamentada en indicadores de resultado 
para personas mayores en el ámbito de la Comunidad Autónoma del País Vasco). En todo caso, si bien los nuevos modelos de inspección pública podrían permitir interpretar el compromiso de la organización para favorecer y facilitar la atención con arreglo a las directrices de la calidad de vida y la ACP, no podrían acreditar objetivamente que el servicio se presta satisfaciendo la percepción doméstica como continuidad de los cuidados en el domicilio, esencialmente observable desde la impresión visual, la valoración de hechos tangibles y la atención en base al respeto. Una demanda del entorno sociofamiliar que, además, debe ser cubierta en dimensión personalizada porque a cada entorno le preocupa principalmente su residente.

En definitiva, el modelo teórico desarrollado se fundamenta en la aplicación de una metodología propia capaz de objetivar la calidad de atención desde la observancia de dos reglas fundamentales:

a. Interpretar la supervisión como una herramienta relacionada no con la atención sanitaria y/o la gestión, sino con la sensación de "hogar" percibida desde las propias personas residentes y/o su entorno sociofamiliar (percepción doméstica de la calidad).

b. Evidenciar que no siempre lo pautado, verbal o documentalmente, se cumple; en términos del saber popular, demostrar que "del dicho al hecho, hay un gran trecho".

A su vez, estas reglas se hacen operativas desde el despliegue de un conjunto de usos cualitativos y cuantitativos:

- Cualitativos:

- Identificación de áreas críticas o de especial sensibilidad para evaluar la calidad y calidez del servicio prestado (tareas de personal gerocultor).

- Aplicar un modelo estándar y sistematizado que permita evaluar la calidad del servicio prestado desde una perspectiva poliédrica (residente, inspección pública y personal del centro).

- Cuantitativos:

- Análisis de series temporales (correlaciones y tendencias para los diferentes niveles de consecuencia, reales o potenciales, de las no conformidades contempladas).

- Panel de indicadores (objetivos y estándares).

\subsection{El modelo teórico de supervisión desde la perspectiva doméstica: qué es y qué no es}

En cierto modo, el modelo desarrollado viene a complementar la evaluación exógena de la calidad desde las certificaciones tipo ISO y/o desde las inspecciones públicas. En ambos casos, los resultados obtenidos se interpretan dentro del contexto propio de las correspondientes auditorías y/o de los procesos de inspección. En ambos casos, también, el soporte documental revisado no permite valorar los usos y costumbres en la ejecución de las tareas profesionales -en definitiva, la cultura asistencial de la organización- porque solo serían sometidos a juicio en caso de reclamaciones escritas (análisis de las medidas correctivas registradas y aplicadas en los expedientes abiertos). El modelo desarrollado quiere huir del reduccionismo propio de las inspecciones y certificaciones externas, por otro parte no modificables porque deben revisar y evaluar todos los procesos de cada centro con arreglo a una metodología y tiempo de análisis concretos. En la medida que se pretende implementar una conciencia profesional, una manera de ejercer la profesión, este tipo de revisiones son insuficientes. En consecuencia, procede el diseño de métodos de evaluación alternativos y fundamentalmente orientados a la prevención como garantía de calidad.

Si bien la supervisión del ejercicio profesional de cuantas personas integran las plantillas de los centros residenciales debería ser efectuada con independencia de la categoría a la que pertenecen, la especial incidencia que el colectivo gerocultor provoca en la apreciación de la calidad asistencial -inherente, además, a la buena o mala imagen del centro- plantea la necesidad de este tipo de herramientas tan finalistas. Como es sabido, el personal gerocultor cubre necesidades vitales, no por la importancia subjetiva que queramos otorgarles sino porque, simplemente, son indisociables del mero hecho de vivir. Los residentes deben disfrutar de una serie de derechos comunes e inalienables como son el derecho a la privacidad e intimidad, a la dignidad, a la autonomía, a la libre elección, a la satisfacción y al estilo de vida propio (De la Cámara, 2003). La observación de la realidad demuestra que la mayoría de las pautas emitidas para procurar el cumplimiento de estos derechos son ejecutadas por auxiliares de geriatría. Este es el hecho diferenciador por el cual se defiende explícitamente el trabajo desempeñado por este colectivo profesional. Directa o indirectamente está presente en todos los procesos de atención y, en consecuencia, es el punto sobre el que gira la atención en un geriátrico y el que, a su vez, más efectivas puede hacer, para el entorno sociofamiliar del residente, la misión, visión y valores del centro residencial.

Sin menospreciar ni infravalorar la aportación de cada categoría profesional al conjunto del geriátrico, es incuestionable el protagonismo desempeñado por el colectivo de auxiliares en lo que a atención directa se refiere. $Y$ lo es en un doble sentido: cualitativamente, porque, en última instancia, son quienes garantizan una vida digna a personas con graves deficiencias físicas y/o psíquicas desde la cobertura de sus necesidades en las actividades de la vida diaria; cuantitativamente, porque constituyen el equipo de profesionales con mayor peso específico de la organización y con presencia garantizada e insustituible a lo largo del día y que, por tanto, 
los convierte en el mayor grupo de contacto con la realidad cotidiana del residente. La interacción entre auxiliares y residentes y/o su entorno familiar es constante y de amplio espectro porque contempla absolutamente todas las caras del sentir humano, de modo que se nos antoja casi imposible la capacidad de aislamiento emocional entre unos y otros. Llega hasta tal punto la simbiosis entre ambos colectivos, residentes y gerocultoras, que la percepción que el núcleo sociofamiliar pudiera tener del centro residencial estará siempre tamizada por las características positivas o negativas de las relaciones entabladas (Gómez Ordoki, 2018).

Hemos defendido la transcendental presencia del personal gerocultor. No obstante, la no obligatoriedad de implantar sistemas preventivos que aseguren la calidad de la atención directa, a diferencia de lo que ocurre en otros ámbitos de la atención geriátrica (planes preventivos de riesgos laborales, de mantenimiento de instalaciones o de seguridad e higiene alimentaria), reduce la garantía asistencial al cumplimiento escrupuloso de cuantos protocolos estime necesarios cada organización, además de los exigidos por ley. En la mayoría de las normativas autonómicas, las referencias al principal recurso humano en la atención residencial se limita - cuando así ocurre- al número de profesionales necesario en función del grado de dependencia. A pesar de tratarse de un recurso indiscutiblemente vital, no se han encontrado métodos para presumir su buen o mal uso. Al parecer, todo pasa por suponer que el hábito de trabajo más extendido es aquel que no produce sino una buena praxis permanente. ¿Este depósito de confianza profesional en el personal gerocultor de cada organización es verosímil? A nuestro entender, no. En caso contrario, sería como imaginar que los responsables de tráfico confiaran plenamente en que cuantos conductores circulan por las carreteras, perfectos conocedores de las limitaciones de velocidad, siempre lo hicieran por debajo de los máximos permitidos. Evidentemente ni el más ingenuo de estos profesionales entendería una red viaria sin controles para detectar "no conformidades" en la conducción.

Se han expuesto las razones por las que se entiende de aplicación una sistemática de supervisión del trabajo del personal gerocultor. En la base del sistema propuesto subyace la idea de atención enfocada a la centralidad de la persona con una aspiración clara: adaptación del centro a la persona residente y no de esta al centro. Pero al entroncar la ACP con la idea de supervisión proactiva corremos el riesgo de confundir una con otra. Procede, por tanto, discriminar qué es y qué no es un modelo de supervisión como el planteado.

La evaluación pública de los servicios - lo que comúnmente conocemos como "inspección"contempla en mayor medida el continente que el contenido (protocolos, procesos, cumplimientos legales o requisitos de norma). Nuestro modelo, en cambio, se ocuparía de la dinámica diaria de atención o, en otras palabras, de los resultados observados en la aplicación de determinadas parcelas del continente (evaluación ex post). No podemos pretender que la inspección pública baje al terreno para inspeccionar lo que se hace in situ todos y cada uno de los días de atención. Esta tarea debe ser delegada en los propios centros que han de constituirse en garantes de una suficiente calidad. En todo caso, en la evaluación ex ante de un centro residencial (procedimiento metodológico ordenado
Tabla 2. Identificando correctamente el modelo propuesto

\section{Qué es}

Un canalizador de la ACP: en el sentido de que se constituye no solo en una herramienta de evaluación de las buenas praxis sino que, asimismo, se preocupa de valorar el "estilo ACP" en la ejecución de las tareas.

Un contraste para las encuestas de satisfacción: la recogida diaria de información sobre áreas críticas de atención, muchas de las mismas contempladas en las encuestas de satisfacción, ayuda a interpretar los resultados obtenidos en ellas).

Un buen evaluador para mejorar en la cobertura de AVD: detectar no conformidades de atención, sistematizar su evaluación, desplegar indicadores de seguimiento y marcar objetivos, ayuda a implementar una consciencia de mejora continua en la prestación del servicio.

Un árbitro para valorar el nivel de desempeño: el modelo evalúa las capacidades del personal gerocultor para configurar equipos de trabajo equilibrados y siempre con el objetivo de "contagiar" las buenas praxis.

Una herramienta de gestión: la toma de datos, la valoración objetiva de resultados y el análisis de gráficos e indicadores deben concretarse en la adopción de una serie de medidas que garanticen la calidad de atención.

Fuente: Elaboración propia.
Qué no es

Un indicador del grado de implementación de la ACP: el avance en la implementación de modelos ACP requiere de otros instrumentos que hagan visible esta filosofía asistencial desde perspectivas con mayor espectro evaluativo.

Un sustitutivo de la percepción de la calidad: la calidad del servicio, entendida en sentido integral y desde una perspectiva multifocal, no debería limitarse exclusivamente a la evaluación sistematizada del trabajo del personal gerocultor.

Un garante, por sí mismo, de las buenas praxis: contar con el método no es suficiente si desde el análisis de las causas no se derivan acciones concretas, en modo y plazos, para rectificar las tendencias negativas.

Un juez para dictar medidas disciplinarias: el personal gerocultor debería sentir cómo el buen hacer, la mejora profesional, va impregnando el know how de la atención; se busca que la proactividad "suplante" a la sanción.

Un método teórico sin aplicación práctica: el modelo no es un ejercicio teórico que describe un modo de proceder alejado de las rutinas diarias que dan sentido a la atención residencial; es un método que busca, sobre todo, la verosimilitud desde el contraste empírico. 
y sistemático para realizar análisis valorativos de los resultados esperados y cuál es el impacto que se genera) deberían conjugarse tanto los intereses de la persona residente y/o su entorno sociofamiliar como de la inspección pública y el centro gestor. Ambas perspectivas de análisis, la evaluación pública y nuestro modelo teórico, deberían producir una similar percepción de la calidad asistencial. Dicha percepción, además, debería adaptarse a una relación de causa-efecto: si el continente es adecuado (resultado de la inspección pública), la evaluación del desempeño del personal gerocultor debería ser, asimismo, satisfactoria (resultados de Habitus).

\section{Metodología}

Como ya hemos explicado, el modelo se proyecta como un arquetipo de gestión de sensaciones para validarlas conforme a su contraste con las descriptivas globales de cada centro residencial. La perspectiva doméstica, o aquella desde la cual, con mayor o menor carga de subjetividad, las personas residentes y/o su entorno sociofamiliar tienden a valorar la calidad del servicio, se constituye en un complemento de evaluación para que la valoración integral de un centro no sea consecuencia exclusiva y directa de perspectivas públicas amparadas en los dictados de la norma. Una sistemática de supervisión del trabajo del personal gerocultor desde los beneficios del rigor que procuran las herramientas de gestión al servicio de la dimensión humana de la atención, no solo se percibe como algo facilitador de la adaptación del centro a la persona residente. Fundamentalmente, se erige en un ejercicio de transparencia, una preocupación por la mejora y una voluntad por satisfacer necesidades no formales que abundan en el cuidado orientado al bienestar. En definitiva, el método es consecuencia de determinadas realidades del sector que muchas veces olvidamos porque la norma nos envuelve hasta casi cegarnos. Por esta razón, el modelo intenta mantener el foco en aquello que prioritariamente es de impacto para residentes y su entorno íntimo. Sirvan los silogismos de la Tabla 3 para enfatizar este interés.

\subsection{Estructura del modelo}

En un contexto de atención residencial a personas mayores, un modelo de supervisión de la calidad asistencial desde la perspectiva doméstica debe dar respuesta a las siguientes cuestiones: qué (no conformidad), quién (personal gerocultor cometedor de la no conformidad) y a quién (residente afectado/a). Esta triple diferenciación de la información deriva en un sistema que debe conjugar el siguiente despliegue de datos:

- Datos de no conformidad (directorio de áreas críticas de supervisión para cada centro residencial).

- Datos de personal (nombre, tipo de personal - propio de plantilla, propio de bolsa y subcontrata-y fechas de alta-baja).

- Datos de residentes (nombre, fechas de altabaja, unidad de convivencia a la que pertenece y atributos de supervisión).

Como herramienta de gestión, el modelo contiene una colección de checklists (tantas como áreas críticas se identifiquen) para la detección de no conformidades que registraremos en una base de datos cuya información se explotará mediante análisis estadístico (González Bolea et al., 2017), el diseño de gráficos adecuados y la identificación de indicadores de seguimiento. No olvidemos que contar con una masa suficiente de datos es una de las premisas fundamentales para que el método pueda ser eficaz. Esta idea de volumen mínimo de datos no es sino una de las condiciones exigidas por cualquier sistema de control de calidad cualesquiera que sean las herramientas que lo hacen operativo (Kaizen, 5S o 6 Sigma, por ejemplo). Si por control de calidad entendemos "el conjunto de los mecanismos, acciones y herramientas realizadas para detectar la presencia de errores" (Infaimon, 2018), nuestro modelo deberá evidenciar la existencia de estos -no conformidades en nuestra terminología- en un entorno productivo en el que nuestro output, la ayuda de tercera para la realización de las AVD, es efímero y no almacenable. A diferencia de lo que ocurre en

Tabla 3. Silogismos que justifican la necesidad de un modelo de supervisión

\begin{tabular}{|l|l|}
\hline Dimensión & Silogismo \\
\hline $\begin{array}{l}\text { Inspección versus perspectiva } \\
\text { doméstica }\end{array}$ & $\begin{array}{l}\text { La inspección pública interpreta la norma/ } \\
\text { la norma no regula sensibilidades ni sensaciones/ } \\
\text { la inspección pública no trata sensibilidades ni sensaciones. }\end{array}$ \\
\hline Domicilio y cuidados & $\begin{array}{l}\text { El entorno sociofamiliar busca la continuidad de los cuidados del domicilio abandonado/ } \\
\text { las residencias son el nuevo domicilio/ } \\
\text { las residencias deben procurar los cuidados como nuevos domicilios. }\end{array}$ \\
\hline Dignidad & $\begin{array}{l}\text { Todos los seres humanos nacen libres e iguales en dignidad/ } \\
\text { las personas mayores, cualquiera que sea su situación psicofísica, son seres humanos/ } \\
\text { las personas mayores deben ser tratadas con dignidad. }\end{array}$ \\
\hline Oportunidad de mejora & $\begin{array}{l}\text { Cada error es una oportunidad de mejora/ } \\
\text { los seres humanos tenemos capacidades y cometemos errores/ } \\
\text { los seres humanos podemos mejorar nuestras capacidades a partir de los errores. }\end{array}$ \\
\hline
\end{tabular}

Fuente: Elaboración propia. 
otros ámbitos del sector terciario, los servicios que dan cobertura a las necesidades básicas de la vida diaria de persona mayores dependientes no adoptan una forma tangible porque, en un porcentaje elevado, se desvanecen una vez prestados. En otras palabras, un cambio postural a un encamado no es comparable con la contratación de un seguro para el hogar: en el primero, el "rastro" se limita a la "evidencia" del cambio si la organización registra este tipo de tareas; en el segundo, un número de póliza sujeto a un justificante de pago y a un contrato mercantil permiten "palpar" el producto. En consecuencia, la trazabilidad del error se complica y obliga a que la detección de los "fallos de producción" se realice desde la supervisión presencial o desde razonamientos deductivos basados en causas objetivas.

La norma ISO 9001 define la calidad como el "grado en el que un conjunto de características inherentes de un objeto cumple con los requisitos", entendiéndose como requisito la "necesidad o expectativa establecida". A este respecto, ¿la perspectiva doméstica, esa sensación de calidad percibida desde las personas residentes $\mathrm{y} / \mathrm{o} \mathrm{su}$ entorno sociofamiliar, no debería ser interpretada como una expectativa? Por otro lado, la calidad pone a los clientes en el centro para cumplir con sus necesidades y mejorar su satisfacción, logro que conseguiremos si son los propios clientes quienes nos ayudan a determinar los requisitos mínimos de calidad. Un entorno favorecedor para la búsqueda de la perfección desde todos los ámbitos de atención (mejora continua), promovido desde el conocimiento como canalizador principal (formación) y operativizado desde los oportunos puntos de control (supervisión), son las garantías del sistema para dar cabida a una atención desde la sensibilidad del entorno sociofamiliar. Llegados a este punto, ¿hay argumentos para seguir pensando que gestión y ACP, por ejemplo, son dos planos de atención que nunca se cruzan?

Un plan de supervisión sin identificación de áreas 0 procesos que supervisar no es operativo. El problema consiste, precisamente, en la definición de un catálogo de tareas a supervisar que se correspondan con una atención acorde a lo que generalmente se interpreta como buena praxis. Probablemente cada organización contemple determinadas subáreas como consecuencia de sus propias experiencias asistenciales, posibilidad que limitaría el análisis desde comparadores (benchs) a las subáreas compartidas.

Cada centro residencial debería relacionar sus áreas y subáreas en función del impacto que ambas dimensiones producen en la percepción de la calidad por parte de los agentes principales que interactúan en la atención. Con este objeto, abrir el centro a las opiniones o sugerencias de residentes y/o familiares también es, en sí misma, una buena práctica. Estandarizar la supervisión conforme a lo que la persona usuaria y su entorno determinen como subáreas de impacto, en un proceso que persiga dar respuesta a las necesidades del cliente $y$, por tanto, intente evitar la preocupante y obligada adaptación de estos a los criterios no pocas veces inamovibles del centro, es una clarísima declaración de intenciones para colocar al cliente en el centro. Recordemos, una vez más, que un centro residencial es el hogar de las personas residentes y, en esa condición, sus voces deben ser escuchadas. Este principio de participación debería complementarse con la perspectiva interdisciplinar de la atención para completar un sistema de supervisión capaz de dar una respuesta integral. Este enfoque profesional consolidaría los diferentes ángulos asistenciales desde la figura del supervisor/a (artículo 17 del vigente Convenio Marco Estatal de Servicios de Atención a las Personas Dependientes y Desarrollo de la Promoción de la Autonomía Personal) que se responsabilizaría del despliegue, registro, seguimiento e interpretación del plan de supervisión. Un cometido alcanzable desde una doble perspectiva que irrenunciablemente debería procurar un feedback mínimo y suficiente con las personas residentes $\mathrm{y} / \mathrm{o}$ su entorno sociofamiliar: supervisión diaria (alerta cotidiana, general y continua) y supervisión programada (concentrar y sistematizar la evaluación de áreas críticas). Esta dualidad en la supervisión origina dos procesos de evaluación claramente diferenciados (Figura 2).

- Supervisión diaria: en la medida que la valoración del desempeño de las personas que forman el equipo a cargo de el/la supervisor/a es una de sus funciones, según el referido artículo 17, la supervisión de cuantas tareas tiene encomendadas el personal gerocultor se constituye en una de las principales competencias de esta figura de control. Dado que en el modelo propuesto asume, además, protagonismo como garante de la calidad asistencial desde la percepción doméstica, el equipo supervisor registrará las incidencias de acuerdo a una determinada clasificación de no conformidades que agruparemos por áreas. En concreto, la supervisión diaria consistirá en el control y registro de cuantas no conformidades se detecten en la actividad asistencial diaria del centro, procedan tanto de las funciones y competencias asignadas a la persona responsable de supervisar como de comunicaciones de terceros (personal del centro, residentes $y / 0$ entorno sociofamiliar propio o ajeno).

- Supervisión programada: para que una cultura asistencial convencida de las sinergias de la mejora continua impregne la organización, la supervisión no debería quedar limitada a meras acciones correctivas de hábitos inadecuados en el ejercicio profesional (supervisión diaria). La supervisión programada (planificación preventiva) se concibe como un proceso técnico que, por una parte, asegura una selección aleatoria de residentes a supervisar en cada subárea de impacto y, por otra, pretende que todas las personas residentes sean homogéneamente evaluadas en función de los días de alta en el año 
(proporcionalidad de la presencia de las personas residentes en las muestras de supervisión o checklist).
Datos de residentes 4 (nombre, fechas de altas y baja, sector, $\mathrm{n}$ - habitación y atributos de supervisión) nombre, fechas jornada y tipo de contrato)
Muestras aleatorias a supervisar y checklist de evaluación (residentes activos

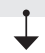

Perspectiva Doméstica de la Calidad de Atención (PDCA)

Plan-Do-Check-Act (PDCA)

Evaluación de servicios prestados
Seguimiento de objetivos

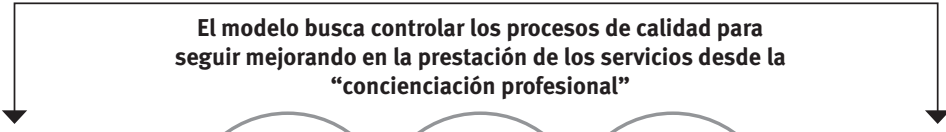

3. ... y que serán vitales para tomar medidas correctoras y ser más eficaces y eficientes en la ejecución de las tareas propias del personal gerocultor.

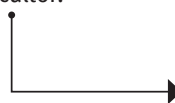

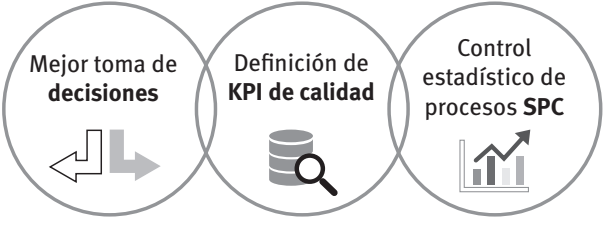

1. Definición de KPI (Key Perfomance Indicator o clave de rendimiento) que nos ayuden a identificar el rendimiento de una determinada acción..
2.... en base a la captura, visualización y análisis de datos, soportado, a su vez, en el control estadístico de procesos y resultados...

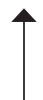

Fuente: Garatu Development y elaboración propia.

Figura 3. Áreas y subáreas de impacto

\section{CUIDADOS DIARIOS}

- Alimentación

- Aseo personal

- Caídas

- Control de esfínteres

- Deambulación y desplazamiento

- Vestido

- Vigilancia y supervisión

\section{SERVICIOS GENERALES}

- Camas

- Habitaciones

- No conformidades de lavandería

\section{CALIDAD}

- Anotaciones

- Desinterés por la información

- Validación mediante firma

\section{BIENESTAR PSICOEMOCIONAL}

- Comunicación respetuosa

- Respeto a la individualidad

- Desarrollo personal
Esquemáticamente representado, a modo de ejemplo, el árbol de trabajos/tareas a supervisar en cada categoría se recoge en la Figura 3.
SUPERVISIÓN PERSONALIZADA

- Bienestar en el cuidado

- Acostar/sueño

- Baño-aseo

- Cambios posturales

- Incontinencia

- Imagen

- Limpieza bucal

- Manicura, pedicura, depilación y podología

- Efectos de uso personal

- Limpieza de sillas, andadores y parque de ayudas técnicas

- Limpieza, orden y

personalización de habitaciones

- Bienestar físico

- Alimentación

- Movilización (ejercicio físico)

- Medicación (SPD y otros)

- Restricciones

\section{SUPERVISIÓN GENERAL}

- Recogida de residuos, pañales y ropa sucia

- Respeto de la intimidad y trato cálido 
Una estructura como la propuesta no debería permanecer inalterable en el tiempo. En sintonía con los procesos de mejora continua, la progresiva consolidación de las buenas praxis por el esperado efecto positivo en la concienciación profesional de las sucesivas evaluaciones de la atención prestada en clave sociofamiliar, iremos "podando" ciertas ramificaciones del árbol (porcentajes de no conformidades recurrentemente asintóticas con el error humano, como más adelante se explica) para injertar nuevos brotes como consecuencia de la detección de nuevas áreas/subáreas de mejora.

Podría interpretarse que la definición de áreas críticas viene a replicar lo que contempla el colectivo marco estatal de servicios de atención a las personas dependientes y desarrollo de la promoción de la autonomía personal como funciones específicas del personal gerocultor. Sin embargo, el contenido del checklist para la evaluación de la praxis asistencial es el valor añadido del modelo. Mientras el convenio colectivo se limita a determinar las tareas $\mathrm{y} / 0$ contenido profesional (el qué), Habitus desglosa la trazabilidad del proceso de atención desde tres ejes evaluativos concretos (calidad técnica, desempeño y respeto o, lo que es lo mismo, el cómo de la prestación del servicio). Ya se ha dicho que el modelo no viene a evidenciar la implantación práctica de la ACP. Se nutre de esta filosofía asistencial, entre otras referencias bibliográficas, para identificar ítems de evaluación que demuestren la preocupación de la organización por aspectos como la libertad de elección, actitud empática, dignidad o cualquiera de las extensiones del concepto de bienestar. Podríamos considerar que la ACP es el envoltorio de la atención y Habitus lo envuelto en términos de percepción doméstica, de continuidad de los cuidados en el nuevo hogar.

\subsection{Composición de las muestras de supervisión ('checklist')}

Ningún centro residencial podría plantearse la completa supervisión de cuantas tareas ejecuta el personal gerocultor y, en menor medida aún, para todas y cada una de las personas residentes. Tal y como se definen los controles de calidad, la posibilidad de condicionar la comercialización/ distribución de un producto a la obtención de unos resultados concretos en controles de calidad previos es una medida cierta; en la atención residencial, la posibilidad de detener la "producción" por incumplimiento de alguno de los parámetros que validan la calidad no es tan inmediata dada la intangibilidad del output. Las tareas que ejecutan las/ los auxiliares de geriatría tienen un fin asistencial irrefutable: dignificar la vida de las personas la calidad del servicio. La ayuda de tercera persona para la realización de las actividades de la vida diaria es un tipo de servicio que no tiene una composición invariable en el tiempo, que consume recursos (tiempo de gerocultor/a) en magnitud aleatoria y que trata de dar respuesta a las necesidades de atención requeridas por personas con dependencia de acuerdo con la visión, misión y valores de cada organización. Aunque en nuestra actividad no podamos aislar el producto para verificar sus "fallos" nada impide que realicemos supervisiones una vez prestado el servicio (valoración ex post facto retrospectivo, cuando todo ha ocurrido antes de que llegue el investigador) o durante el proceso de atención (valoración ex post facto prospectivo, cuando la causas que motivan una no conformidad están en marcha pero todavía no ha habido desenlace). En ambos casos, la información recabada nos dotaría de datos para evaluar la tendencia e implementar medidas correctoras que nos ayudarán en la minimización de las no conformidades. Empíricamente se demuestra que este tipo de controles estimulan la concienciación profesional como garantía para una reducción progresiva de las praxis no ajustadas a nuestros parámetros de calidad. Nunca alcanzaremos el umbral cero en la detección de no conformidades porque las personas, por definición, somos falibles. Pero este tipo de chequeos a posteriori, basados en la extracción aleatoria de registros de supervisión, son facilitadores de culturas identificadas con la mejora continua como máximo dinamizador de las buenas prácticas.

Ya hemos adelantado la imposibilidad técnica y material de supervisar todos los quehaceres profesionales del personal gerocultor. Para analizar la totalidad de las tareas, el equipo de supervisión debería estar compuesto por un número de profesionales exactamente igual al del colectivo a evaluar (un profesional evaluando, al mismo tiempo, lo que hace otro), lo que supone un coste inasumible desde cualquier punto de vista. Al problema económico se uniría un tamaño de población absolutamente inmanejable, como demuestra el cálculo de la Tabla 4.

Como en otras muchas parcelas de investigación, las técnicas estadísticas nos facilitan el análisis para determinar el comportamiento de la población e inferir sus parámetros. Así, el modelo prevé la obtención de muestras aleatorias con reemplazamiento y afijación proporcional a la capacidad de cada unidad de convivencia del centro (se garantiza la presencia de residentes de todos los módulos convivenciales que componen el geriátrico). La dificultad radica en la definición del tamaño de muestra necesario para que sea estadísticamente representativa de una población de la que no conocemos sus estadísticos principales (media y desviación). En estos casos, para una variable dicotómica como la que nos ocupa ( $p=$ conformidad / $q=1-p=$ no conformidad), la expresión que determina un tamaño de muestra suficientemente significativo es

$$
\mathrm{n}=\frac{\mathrm{N}_{\mathrm{p}}}{1+\frac{\mathrm{e}^{2}\left(\mathrm{~N}_{\mathrm{p}}-1\right)}{\mathrm{Z}^{2}\left(\mathrm{~S}^{\prime}\right)^{2}}},
$$


Tabla 4. Ejemplo de tamaño de población

\begin{tabular}{|c|c|c|}
\hline Concepto & Valor & \multirow{5}{*}{$\begin{array}{l}\text { - Cada residente, cada día, con cada gerocultor/a y } \\
\text { cada tarea, debe ser evaluado con un mismo patrón } \\
\text { de supervisión (checklist de evaluación). Como nos } \\
\text { interesa cuantificar las buenas praxis, la variable es } \\
\text { dicotómica (conforme o no conforme) para el conjunto } \\
\text { de la atención. Las descriptivas para cada subárea } \\
\text { crítica serán consecuencia del número mensual de } \\
\text { observaciones como reparto de la muestra anual total. } \\
\text { - El número teórico de supervisiones diarias, cualquiera } \\
\text { que sea el tamaño residencial, raramente excedería de } \\
\text { las } 10-12 \text { supervisiones diarias de media. Una cifra que } \\
\text { hace muy asumible la implantación del modelo. }\end{array}$} \\
\hline Capacidad del centro & 100 & \\
\hline $\begin{array}{l}\text { Porcentaje de residentes a } \\
\text { supervisar }\end{array}$ & $80 \%$ & \\
\hline $\begin{array}{l}\text { Subáreas críticas } \\
\text { - De ejecución diaria } \\
\text { - De ejecución intermitente }\end{array}$ & $\begin{array}{l}15 \\
12 \\
3 \text { (de media, una vez cada tres días) }\end{array}$ & \\
\hline Tamaño de población & $100 * 80 \% *(12+3 * 1 / 3){ }^{*} 365=379.600$ & \\
\hline
\end{tabular}

Fuente: Elaboración propia.

donde $S^{\prime}=0,5$-porque maximiza el producto $\mathrm{p}^{\star}(1-\mathrm{p})-, Z$ es el valor tipificado que deja un área igual al nivel de confianza entre las cotas $+\alpha / 2$ y $-\alpha / 2$ en una distribución de Gauss, y e es el margen de error entre la media muestral y la verdadera media de la población. Como cada subárea de impacto identificado es un servicio diferenciado, extraeremos una muestra para cada una de ellas que, de acuerdo con la expresión de $n$, contendrán un número de elementos adaptado a la presencia de residentes susceptibles de supervisión (el número de personas residentes independientes, o capaces de realizar por sí solas las actividades implícitas en la subárea a supervisar, podría modificar marginalmente el tamaño de la muestra)

Empíricamente se demuestra que el tamaño de muestra es fundamentalmente sensible al margen de error. Para niveles de confianza superiores a un $95 \%$, cada variación marginal del error de un $1 \%$ produce un incremento del tamaño de muestra sensiblemente superior a un mismo incremento marginal en el nivel de confianza. Es más que probable que plantear la supervisión en combinación confianza-error de 99\%-1\% no haga viable la asunción del número de supervisiones propuesto (tamaño mínimo de muestra de 32 elementos y máximo de 46) por cuanto de dedicación de tiempo de supervisor/a pudiera suponer. No es una composición que aliente la implementación del método porque la carga de trabajo derivada sería inasumible para la inmensa mayoría de las organizaciones. Sin apenas perder garantías de fiabilidad, las combinaciones 98\%-2\% 0 97\%-3\% podrían ser los estándares aconsejables por una doble razón: permiten distribuir las supervisiones a lo largo del día sin hipotecar las tareas y responsabilidades del personal supervisor y, asimismo, originan suficiente número de supervisiones para proceder a la distribución de las no conformidades por subáreas críticas y poder detectar ámbitos asistenciales susceptibles de mejora (interesa enfocar la supervisión desde perspectivas lo más poliédricas que sea posible para, de esta manera, incorporar en el juicio de la calidad prestada el mayor abanico de sensibilidades de las personas residentes y/o su entorno sociofamiliar). En todo caso, aquellas organizaciones que incrementen el tamaño de muestra sobre el teóricamente correspondiente a la capacidad del centro reducirán la amplitud del intervalo de confianza que contiene el verdadero valor de la media de la población y, en consecuencia, afinarán en mayor medida el porcentaje esperado de las no conformidades, lo que, en definitiva, no es sino medir el grado de avance de la cultura de las buenas praxis asistenciales.

Decidir implantar un número menor de subáreas no origina reducir la muestra anual total. Dado que la muestra anual es prácticamente constante para cada combinación confianza-error, a medida que redujéramos el número de subáreas incorporadas aumentaríamos la muestra aleatoria mensual de cada una de ellas. El número total de supervisiones seguiría siendo prácticamente el mismo y, si bien estrechamos el intervalo de confianza por efecto de un mayor tamaño muestral, perdemos diversidad de perspectiva en la medida en que limitamos el análisis precisamente a las áreas seleccionadas. Por consiguiente, para facilitar la evaluación transversal de la calidad, se aconseja que la implantación del modelo no desprecie ninguna de sus subáreas. Cada organización fijará una combinación de nivel de confianza y margen de error que no colapse el proceso asistencial y pueda ser asumida por el equipo de supervisión. Como regla general, convendría no exceder de las 30 supervisiones mensuales por subárea y de las 15 diarias en total cualquiera que fuera su composición (presencia de cada subárea en la muestra); en la práctica, la validez de la inferencia estaría garantizada con no más de 10-12 como número medio de supervisiones por día.

El software que permite la operatividad práctica del modelo lanza listados aleatorios que atienden a dos modos diferenciados de selección: captura de residentes para chequeos de servicios diarios (subáreas críticas o de impacto que se corresponden con tareas diariamente ejecutadas) y muestras compuestas por residentes a quienes se atiende conforme a una programación intermitente (por ejemplo, la planificación de la manicura y pedicura). La Tabla 5 ilustra las rutinas para la evaluación de la calidad asistencial y la detección de no conformidades: 
Tabla 5. 'Checklist' mensual de evaluación (dos ejemplos de trazabilidad de criterios*)

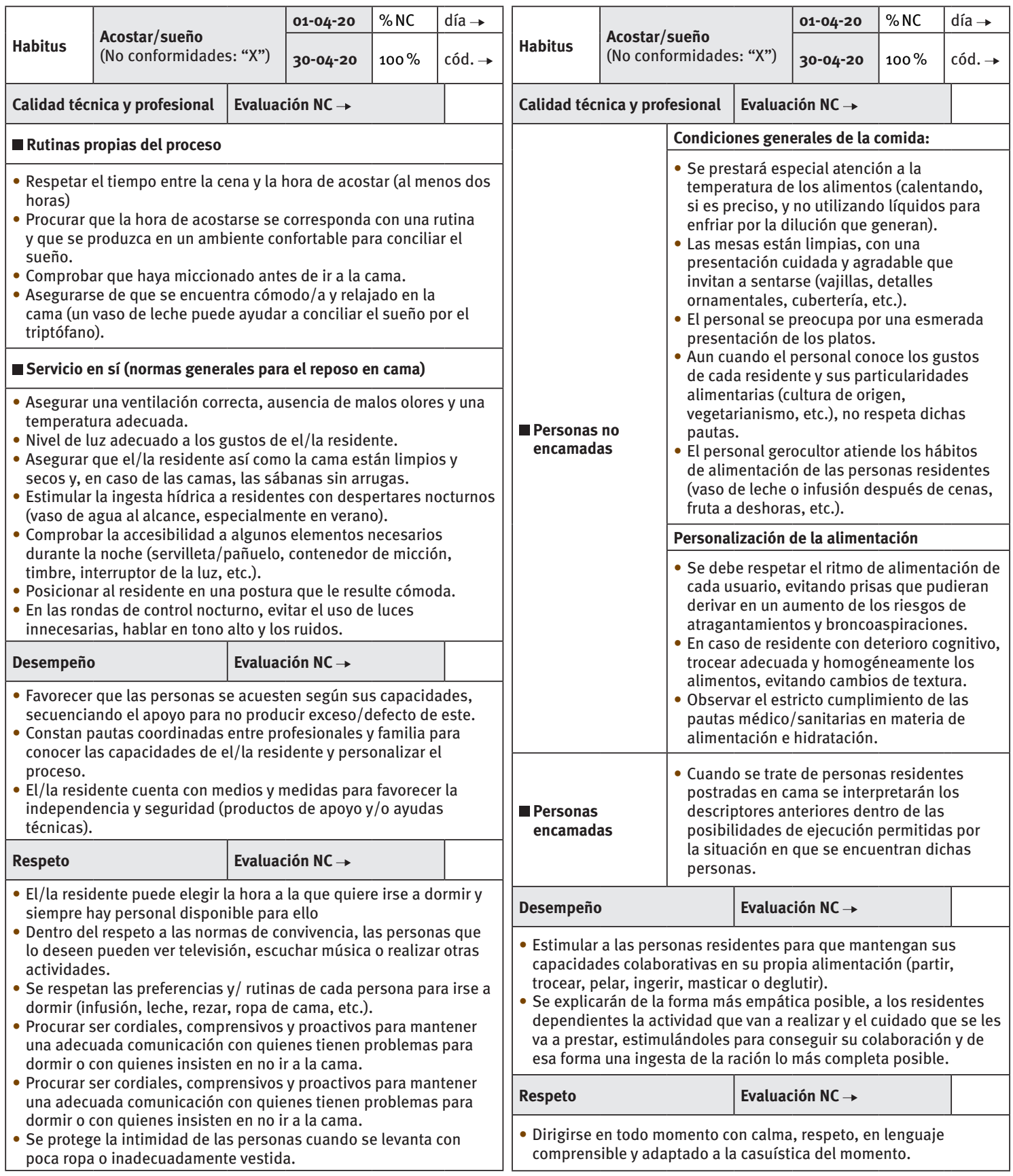

* La configuración de los ítems de las quince subáreas críticas identificadas está, en parte, recogida de Navarro (2019), Gil Gregorio et al. (2013), Trinidad (2007) y Gómez Martín y Díaz Vega (2011).

Fuente: Elaboración propia.

\subsection{Evaluación de la no conformidad}

El modelo edifica un sistema evaluativo de tres plantas. Cada planta tiene mano izquierda y derecha para presentar una valoración secuenciada (evaluación $\rightarrow$ calidad $\rightarrow$ contexto) que se repetiría evaluar la consecuencia de la no conformidad vendrían relacionadas en un documento de soporte que se anexaría a la muestra aleatoria de cada subárea para fijar la trazabilidad de la calificación de la praxis profesional.
La planta o nos dotará de argumentos para comprobar si la premisa "a mayor número de supervisiones, mayores probabilidades de minimizar la detección de no conformidades" es tan cierta que casi nadie aceptaría una interpretación a priori en sentido contrario. En las plantas 1 y 2 evaluaremos el servicio conforme al trinomio observacional calidaddesempeño-respeto. El resultado cualitativo final para cada una de estas dimensiones se obtendrá en base a la interpretación fiel de los ítems que integran los hitos a supervisar en cada subárea de impacto. 
Fuente: Elaboración propia.

Evidentemente, reducir a su mínima expresión la subjetividad implícita en la valoración acreditará los resultados hasta hacerlos verosímiles. El modelo aportará pruebas para detectar aquellos comportamientos laborales, hábitos de trabajo, enfoques de atención o cualesquiera modos profesionales de proceder que originen, de modo objetivo y generalmente aceptado desde razonamientos y percepciones basados en la lógica asistencial, un perjuicio real o potencial en los planos físico y/o psicoemocional de las personas residentes. Los criterios para determinar qué valor de la escala cualitativa de valoración debemos asignar a cada dimensión evaluable (calidad, desempeño y respeto), serán los siguientes:

- Leve: un efecto perjudicial mínimo que no produzca, en modo efectivo, un empeoramiento en el estado de salud de las personas residentes, una minoración de su bienestar psicoemocional o una pérdida perceptible del respeto a la dignidad humana, o que la recurrencia de las no conformidades, no corregida por omisión, dejadez o descuido, origine o pudiera originar un descontento, molestia y/o queja-reclamación verbales por parte del entorno sociofamiliar de la persona residente.

- Moderado: un efecto perjudicial medible objetivamente o intuitivamente evaluable que provoque o hubiera podido provocar, en modo efectivo, un empeoramiento transitorio pero recuperable del estado de salud de las personas residentes (según criterio del personal sanitario o de la propia persona supervisora por conocimiento de causa), un agravante para la estabilidad psicoemocional que supongan nuevas pautas médicas (administración de psicofármacos, aumento de dosis u otras) o un menoscabo explícito del respeto a la dignidad humana, o que la recurrencia de las malas praxis, no corregida por omisión, dejadez o descuido, origine o pudiera originar un descontento, molestia y/o queja-reclamación escritas por parte del entorno sociofamiliar de la persona residente.

- Grave: un evidente efecto perjudicial, objetivamente valorable desde la simple observación visual o intuitivamente evaluable, que provoque o hubiera podido provocar, en modo efectivo, un empeoramiento definitivo e irreversible del estado de salud de las personas residentes (según criterio del personal sanitario, de la propia persona supervisora por conocimiento de causa o del entorno sociofamiliar de la persona residente), un perjuicio incuestionable para el bienestar y la estabilidad psicoemocional que suponga nuevas pautas médicas (administración de psicofármacos, aumento de dosis u otras) o que haya sido causado por un patente desinterés por la historia de vida de la persona residente o, asimismo, una absoluta falta de respeto a la dignidad humana, o que la recurrencia de las malas praxis, no corregida por omisión, dejadez o descuido, origine o pudiera originar un descontento, molestia y/o queja-reclamación escritas presentadas ante la administración pública por parte del entorno sociofamiliar de la persona residente, si así son consideradas por el propio ente público.

Tres son las dimensiones evaluables; tres, también, las categorías cualitativas de valoración. Veintisiete 
Tabla 6. Criterios de evaluación conjunta de la no conformidad

\begin{tabular}{|c|c|c|c|c|}
\hline Intervalos de asignación & \multicolumn{2}{|c|}{ Prevalencia indiscriminada } & \multicolumn{2}{|c|}{ Prevalencia selectiva } \\
\hline $\begin{array}{l}\text { Cada uno de los ítems, entendidos los mismos con un } \\
\text { mismo peso específico, participa en la medición del } \\
\text { efecto conjunto como sumando al valor de ponderación } \\
\text { previamente asignado a cada nivel de evaluación }\end{array}$ & \multicolumn{2}{|c|}{$\begin{array}{l}\text { Considera que el nivel máximo de } \\
\text { gravedad en uno cualquiera de los } \\
\text { ítems es suficiente para interpretar } \\
\text { el conjunto de la tarea en idéntico } \\
\text { sentido. }\end{array}$} & \multicolumn{2}{|c|}{$\begin{array}{l}\text { La evaluación conjunta es coincidente } \\
\text { con la del nivel máximo de gravedad } \\
\text { para aquellos ítems considerados de } \\
\text { "especial significación" en la ejecución } \\
\text { de la tarea (sombreados). }\end{array}$} \\
\hline \multicolumn{5}{|l|}{ Ejemplo de cálculo de evaluación } \\
\hline \multirow{3}{*}{$\begin{array}{l}\mathrm{n}: \quad \text { número de ítems de evaluación }(\mathrm{n}=3) \\
\mathrm{p}: \quad \text { ponderación de cada nivel } \\
\quad(\text { leve }=1, \text { moderado }=2 \text { y grave }=3) \\
\mathrm{S}: \quad \text { suma de ponderaciones }(\mathrm{S}=2+2+1=5)\end{array}$} & \multicolumn{2}{|c|}{ Ejemplo de evaluación } & \multicolumn{2}{|c|}{ Ejemplo de evaluación } \\
\hline & Ítem & Consecuencia & Ítem & Consecuencia \\
\hline & Calidad & Moderada & Calidad & Leve \\
\hline \multirow{2}{*}{$\begin{array}{l}\text { Intervalos para cada nivel } \\
\text { - leve } \rightarrow[1,3] \\
\text { - moderado } \rightarrow[4,6] \\
\text { - grave } \rightarrow[7,9]\end{array}$} & Desempeño & Moderada & Desempeño & Grave \\
\hline & Respeto & Grave & \multirow{2}{*}{\multicolumn{2}{|c|}{ Evaluación: moderada }} \\
\hline Evaluación total: $5 \rightarrow$ moderado $(4 \leq 5 \leq 6)$ & \multicolumn{2}{|c|}{ Evaluación: grave } & & \\
\hline
\end{tabular}

Fuente: Elaboración propia.

serían los posibles grupos de evaluación que se pueden obtener como combinación de los tres niveles para las tres dimensiones $\left(\mathrm{VR}_{\mathrm{m}}^{\mathrm{n}}=\mathrm{m}^{\mathrm{n}}=3^{3}=\right.$ 27). Sin embargo, el modelo contempla una única evaluación conjunta por una razón sustancial: simplificar la casuística interpretativa a un nivel suficientemente significativo desde la ponderación de la evaluación conforme a diferentes criterios descriptivos (estandarización para la sencillez de manejo). Lógicamente, en una dinámica de benchmarking el criterio de ponderación deberá ser común a cuantos centros residenciales participen en la compartición de resultados. Los tres criterios considerados son los que recoge la Tabla 6.

\subsection{Bases de datos}

Gestionar con rigor es trabajar con datos objetivos, fidedignos y fiables. Pero perderíamos el valor del esfuerzo por registrar siendo fieles a la realidad de los hechos observados si no volcáramos la información en los soportes adecuados. Diseñar un método para que la explotación de los datos sea ágil, flexible e interactiva es determinante para que la información se procese prácticamente de inmediato y ofrezca resultados en tiempo real para la toma de decisiones.

Dependiendo del margen de error y del nivel de confianza con los que queramos trabajar, respetado el valor mínimo aconsejable según datos de la Tabla 7, el total de supervisiones programadas podría ser ciertamente cuantioso. Ante esta presunción, alguien podría pensarse que la información a registrar en las bases de datos será tan voluminosa que hipotecará buena parte de la jornada laboral de la persona responsable de la supervisión. Desde nuestra experiencia profesional en el manejo de este tipo de herramientas, intentaremos disuadir a quienes más recelan de su utilidad práctica y/o a quienes más defienden una inasumible dotación de recursos para la implementación de esta metodología: por un lado, empíricamente se demuestra que los hábitos profesionales contraproducentes no están instalados por defecto en las organizaciones y, por consiguiente, su detección debería ser residual como consecuencia de una cultura asistencial instaurada desde procesos y protocolos generalmente aceptados en el sector; por otro lado, también desde la práctica, se comprueba que el uso de estas sistemáticas de evaluación desembocan en un "contagio" progresivo de las buenas prácticas como garantía de calidad. En una experiencia similar desarrollada en un geriátrico de Gipuzkoa, se observó que las no conformidades, además de registrar una reducción numérica gradual año tras año, cambiaban de categoría hasta concentrarse fundamentalmente en "leves" y "moderadas", al tiempo que el peso específico de las "graves" era cada vez menor. En concreto, el primer año de implementación se documentaron aproximadamente dos mil no conformidades correspondientes a las cuatro áreas críticas de la supervisión diaria (cuidados diarios, servicios generales, calidad y bienestar psicoemocional), lo que arrojó una tasa de detección de poco más del $2 \%\left(\frac{2000}{60^{\star} 4^{\star} 365}=2,28 \%\right)$.

En un ejemplo como el expuesto, en el que la dinámica de supervisión no es consecuencia de un procedimiento sino resultado de la acción correctiva por la detección de procederes profesionales no acordes a estándares de calidad, la concienciación profesional del personal gerocultor se supone pero no se prueba. En un contexto como el comentado es más que probable que la ausencia de una cultura de supervisión favorezca la detección de no conformidades desde la perspectiva doméstica porque, precisamente, no hay descriptores claros para discriminar las buenas praxis de las que no lo son. Por tanto, cuando se transita de un modelo indefinido a uno que identifica oportunidades de mejora, es de esperar que se descubran innumerables ejecuciones de tareas por debajo del estándar de calidad adoptado. La evolución temporal estimada en el número y gravedad de las no conformidades, como consecuencia de una cultura asistencial autoevaluada, podría aproximarse a la Figura 5. 


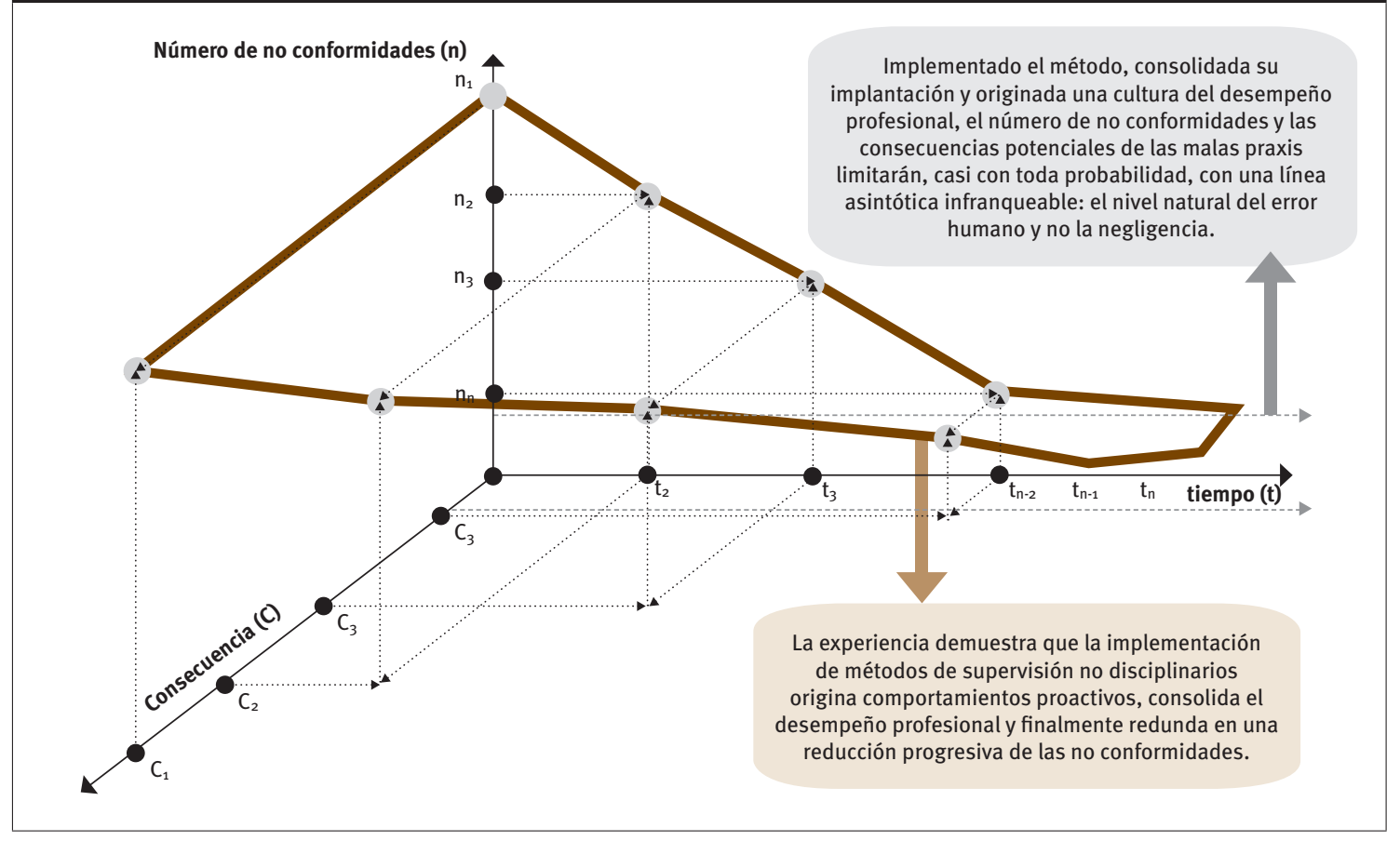

Fuente: Elaboración propia.

El porcentaje de supervisiones que derivan en una no conformidad no debería superar, bajo ningún pretexto ni condición, la tasa del $10 \%$. Si así fuera, la calidad del servicio sería indiscutiblemente insuficiente. Nadie compraría en el mercado ningún bien ni servicio que presentara defectos en una de cada diez unidades producidas y, mucho menos aún, en una de cada diez unidades vendidas. En nuestro modelo, el control de la unidad producida se correspondería con la valoración ex post facto prospectivo (evaluación presencial); por su parte, analizaríamos cada unidad vendida, entendida la misma como servicio prestado imposible de "retirar del mercado" por su condición efímera e intangible, desde la valoración ex post facto retrospectivo (evaluación deductiva).

Suponiendo que el centro residencial cuenta con 150 plazas y 15 son las subáreas de impacto, la muestra diaria estaría compuesta por 9 residentes, dados un nivel de confianza del $98 \%$ y un margen de error del $2 \%$ (datos de la Tabla 7). Cada año, a razón de una tolerancia máxima del $10 \%$ (entenderemos como tolerancia estándar el porcentaje máximo de no conformidades que estamos dispuestos a permitir, calculado como cociente entre el número de no conformidades detectadas - desglosadas o no por nivel de consecuencia potencial-y el número de supervisiones realmente realizadas), podrían ser registradas en torno a 330 no conformidades. Unas cifras nada contrastables porque no se han encontrado referencias bibliográficas para la definición de patrones máximos generalistas en la detección de fallos en la producción de bienes o servicios. La documentación consultada, absolutamente contextualizada en el proceso productivo en cuestión, poco o nada aporta al respecto. Así, nos encontramos con propuestas como las del modelo Seis Sigma, cuya meta es llegar a un máximo de 3,4 defectos por millón de eventos u oportunidades, un objetivo absolutamente inalcanzable en nuestro modelo por el efecto esperado de las connotaciones propias de la atención residencial a mayores.

Un $10 \%$ se antoja incluso demasiado para un tipo de trabajo extremadamente protocolizado y que, por añadidura, cuenta con una secuencia de ítems - pistas- que soportan, conforme a un guion, la evaluación objetiva de la calidad prestada. En semejantes circunstancias, debería fijarse el umbral de tolerancia de las no conformidades en no más de un 5\%-6\%. Cabría esperar, además, que anualmente fuera reduciendo su presencia por la incidencia de un colectivo profesional cada vez más concienciado en la mejora continua. En la Tabla 7 podemos observar la secuencia de no conformidades si su tasa de decrecimiento anual fuera del $1 \%$ hasta alcanzar un nivel asintótico del $2 \%$.

La Tabla 7 contiene los tamaños mínimos de muestra aconsejables para diferentes márgenes de error y niveles de confianza. No obstante, estos tamaños muestrales deberían verse afectados al alza en medida similar al valor porcentual de las supervisiones no realizadas. Quienes gestionan centros residenciales son perfectos conocedores de la variabilidad que producen toda índole de factores endógenos y exógenos presentes en la actividad residencial. Con frecuencia no despreciable, las personas residentes, aleatoriamente seleccionadas para formar parte de la muestra, 
Tabla 7. Total esperado de no conformidades en función de la tasa de tolerancia admitida*

\begin{tabular}{|c|c|c|c|c|c|c|c|c|c|c|c|c|c|}
\hline \multirow{2}{*}{ Capacidad $^{\star *}$} & \multirow{2}{*}{$\begin{array}{c}\text { Nivel } \\
\text { confianza }\end{array}$} & \multirow{2}{*}{$\begin{array}{c}\text { Margen } \\
\text { error }\end{array}$} & \multirow{2}{*}{$\begin{array}{c}\text { Muestra } \\
\text { diaria }\end{array}$} & Año 1 & Año 2 & Año 3 & Año 4 & Año 5 & Año 6 & \multirow{2}{*}{$\cdots$} & Año 19 & Año 20 & Total \\
\hline & & & & $6 \%$ & $5 \%$ & $4 \%$ & $3 \%$ & $2 \%$ & $2 \%$ & & $0 \%$ & $0 \%$ & \\
\hline \multirow[t]{5}{*}{$0-300$} & $95 \%$ & $5 \%$ & 1 & 22 & 18 & 15 & 11 & 7 & 7 & $\ldots$. & 7 & 7 & 178 \\
\hline & $96 \%$ & $4 \%$ & 2 & 44 & 37 & 29 & 22 & 15 & 15 & $\ldots$. & 15 & 15 & 372 \\
\hline & $97 \%$ & $3 \%$ & 4 & 88 & 73 & 58 & 44 & 29 & 29 & $\ldots$. & 29 & 29 & 727 \\
\hline & $98 \%$ & $2 \%$ & 9 & 197 & 164 & 131 & 99 & 66 & 66 & $\ldots$. & 66 & 66 & 1.647 \\
\hline & $99 \%$ & $1 \%$ & 38 & 832 & 694 & 555 & 416 & 277 & 277 & $\ldots$. & 277 & 277 & 6.929 \\
\hline
\end{tabular}

*Como más adelante comprobaremos, la disconformidad no se producirá por comparativa con el número de no conformidades detectado, sino con la puntuación total límite tolerada que, a su vez, será el producto de dicho número por la ponderación de la consecuencia grave.

${ }^{*}$ Según los datos de la Tabla 7, para combinaciones de nivel de confianza y margen de error diferentes a $99 \%$ y $1 \%$ respectivamente, el tamaño de muestra es prácticamente independiente de la capacidad del centro y del número de subáreas incorporadas. Trabajar con muestras medias diarias de 4 a 9 supervisiones, asumibles en la mayoría de los centros residenciales, proporciona suficiente significación estadística para evaluar la calidad de la atención desde la perspectiva del entorno sociofamiliar.

Fuente: Elaboración propia.

podrían no reunir las condiciones necesarias para evaluar su atención. Las razones, diversas conceptual y temporalmente, se pueden resumir en las siguientes: baja (se produce la baja de la persona residente con fecha anterior a la fecha de supervisión) e imposibilidad (causa objetiva de fuerza mayor que impide la prestación del servicio $y$, por consiguiente, la evaluación del mismo). También deberíamos contemplar la posibilidad de que la supervisión no se realice sin que se encuentren motivos que justifiquen este descuido (negligencia). Lógicamente, para asegurar un tamaño de muestra ajustado a tantos elementos como requieran el nivel de confianza y el margen de error manejados tendremos que rectificar su cálculo previo con la media de supervisiones no realizadas. Para ello, mantendremos el correspondiente registro histórico por subárea crítica.

En resumen, la base de datos del modelo se desdobla en dos tablas interrelacionadas de datos que se configuran en las fuentes de información para la obtención de gráficos e indicadores de seguimiento, tal y como recoge la Tabla 8.

\subsection{Explotación de la información: listados y gráficos}

Hemos generado un entramado teórico para la evaluación de la calidad desde la percepción y la sensibilidad del entorno sociofamiliar. Podría entenderse que esta perspectiva de evaluación es absolutamente necesaria porque transciende la esfera grupal y/o organizacional que abordan las inspecciones públicas para llegar a la esfera personal (aquella que vela por el cumplimiento de las expectativas de atención del entorno sociofamiliar, un cometido que adoptará como propia la mirada de aquel para evaluar empáticamente los servicios prestados cuando familiares o amigos no están presentes en el centro por criterios organizativos). En mi opinión, cada centro debería exponer a su personal, con total transparencia, los resultados obtenidos con la experiencia para incentivar una dinámica de mejora continua. Un ejercicio semejante también sería de total interés para los clientes (residentes, entorno sociofamiliar y/o Administraciones Públicas concertadoras de servicios), aunque mi experiencia profesional no me permita albergar muchas esperanzas a este

Tabla 8. Datos a registrar

\begin{tabular}{|c|c|c|c|c|}
\hline Supervisión & \multicolumn{3}{|l|}{ Tamaño de muestra } & Datos \\
\hline \multirow[t]{3}{*}{ Programada } & $\begin{array}{l}\text { Supervisiones no } \\
\text { realizadas }\end{array}$ & $\begin{array}{l}\text { Subárea } 1 \\
\text { Subárea } 2 \\
\text { Sub.............. } \\
\text { Subárea n }\end{array}$ & $\begin{array}{l}\operatorname{tnr}_{1} \\
\operatorname{tnr}_{2} \\
\ldots . \\
\operatorname{tnr}_{n}\end{array}$ & \multirow{2}{*}{$\begin{array}{l}\text { Datos troncales a cada tipo de supervisión } \\
\text { - Día de no conformidad } \\
\text { - Trabajador/a cometedor/a } \\
\text { - Residente afectado/a } \\
\text { - Área asistencial/subárea de impacto } \\
\text { - Tipo de evaluación (presencial/deductiva) }\end{array}$} \\
\hline & \multirow{2}{*}{$\begin{array}{l}\text { Tamaños de muestra } \\
\text { previo }(n)\end{array}$} & \multirow{2}{*}{\multicolumn{2}{|c|}{ 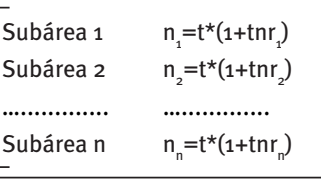 }} & \\
\hline & & & & $\begin{array}{l}\text { Datos supervisión programada } \\
\text { - Calidad del servicio (grave/moderada/leve) }\end{array}$ \\
\hline \multirow[t]{2}{*}{ Diaria } & \multirow{2}{*}{\multicolumn{3}{|c|}{$\begin{array}{l}\text { No hay tamaño de muestra porque se trata de una de las } \\
\text { funciones asignadas a la figura profesional de supervisor/a } \\
\text { de residencias. Es, por tanto, un quehacer diario y con la } \\
\text { intensidad requerida por la organización. }\end{array}$}} & - Respeto (grave/moderada/leve) \\
\hline & & & & $\begin{array}{l}\text { Datos supervisión diaria } \\
\text { - Consecuencia (grave/moderada/leve) }\end{array}$ \\
\hline
\end{tabular}

Nota: $\operatorname{tnr}_{\mathrm{i}} \rightarrow$ media histórica de tasas de supervisiones no realizadas en cada subárea de impacto.

Fuente: Elaboración propia. 
respecto. A veces, con mayor presencia de la aconsejable, ni las lecturas proactivas del recorrido de mejora iniciado ni consignas tan estimulantes como "estamos en la buena senda" son argumentos suficientes para dar cauce a la aplicación de estas sistemáticas de evaluación. Este tipo de actitudes se contraponen a los principios de la responsabilidad social corporativa, por otra parte una demanda social con la que todas las organizaciones tenderán a alinearse ideológicamente. Sin embargo, en no pocas ocasiones, la realidad no es sino consecuencia de unos comportamientos culturalmente tan arraigados que resultaría iluso pensar en cambiarlos; en otras palabras, es más difícil asumir responsabilidades y compromisos como consecuencia del impacto negativo de nuestra gestión en el cliente (detección, gestión y reducción de no conformidades) que optar por una estrategia de huida hacia adelante basada en actitudes preocupadas por no tirar piedras a nuestro propio tejado. ¿Medimos el grado de compromiso de la organización para cubrir las expectativas del entorno sociofamiliar o solo decimos que lo hacemos desde nuestra visión, misión y valores?
El modelo de supervisión contempla varios módulos de explotación de datos. Básicamente, estos módulos hacen referencia a dos formatos de información: gráficos y paneles de indicadores. Aunque, también, se filtran datos para obtener información grupal o personal (trabajador/a y residente). El sistema diseñado es adaptativo: acepta tanto la incorporación de nuevas áreas de impacto desde los criterios marcados por los propios centros gestores como la supresión o desconsideración de otras. Asimismo, la secuencia baja-alta también se producirá porque el centro sustituirá progresivamente el seguimiento de áreas críticas que ya han conseguido un nivel asintótico de no conformidades (cuando la buena praxis es un hecho constatable) por nuevas áreas a evaluar. El modelo se irá renovando desde la propia experiencia adquirida para responder a necesidades propias y no a exigencia alguna de enfoques importados. Aun cuando se presuma una transformación tan continuada, la salida de información permanecería invariable para adaptarse a la Figura 6.

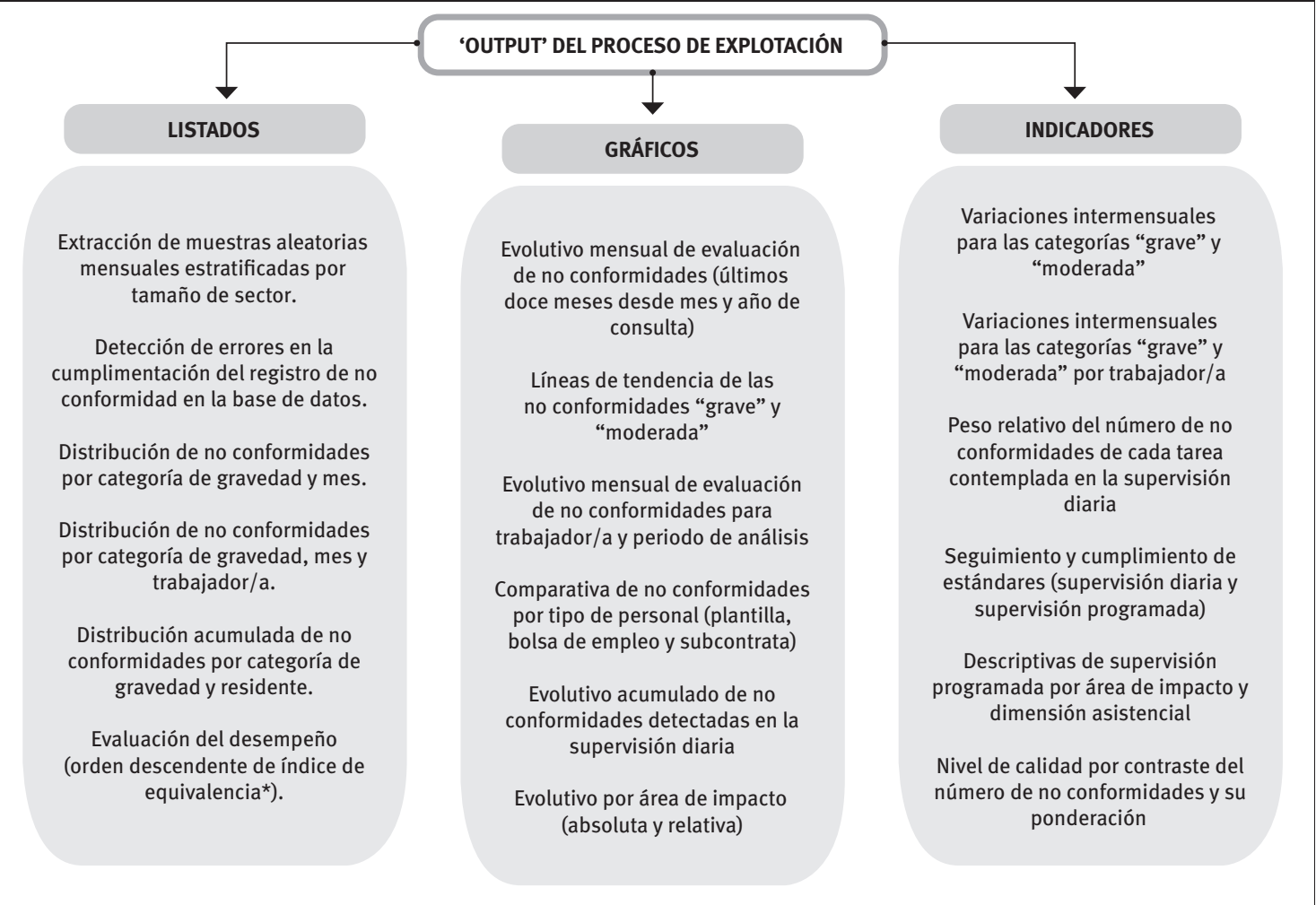

* Índice equivalencia, ie $=\frac{\mathrm{e}}{\mathrm{e}_{\max }}$, donde e $=\frac{\sum_{\mathrm{i}=1}^{\mathrm{i}=\mathrm{n}} \mathrm{po} \mathrm{*}^{\mathrm{j} l}{ }^{*} \mathrm{pnc}}{\mathrm{ns}}$ y $0 \leq \mathrm{ie} \leq 1$

- \% periodo de observación (po):

$\bullet \%$ jornada laboral (jl):

- ponderación no conformidades (pnc):

Fuente: Elaboración propia. 


\section{Rompiendo el mito supervisión presencial-buena praxis frente a supervisión deductiva-no conformidad}

Tradicionalmente se ha interpretado que en la cultura mediterránea las personas somos propensas a relajar nuestra actitud si no nos sentimos "vigiladas". Aún hoy, a pesar de la superación de muchos estereotipos socioculturales, sigue siendo relativamente frecuente toparse con apreciaciones similares. Esta falta de confianza en las actitudes profesionales promueve pensamientos que parten de aforismos trasnochados para extender la idea de que solo se garantiza un nivel mínimo de negligencias y/o malas praxis si la supervisión es presencial -cuando el gato no está, los ratones bailan, que diría alguna persona mayor de nuestros centros- $y$, además, toma nota de cuanto observa. Esta es una actitud tan fiscalizadora que no presume una conducta mínimamente vocacional y empática del personal gerocultor, por otra parte ejecutor de prácticas probablemente mejorables desde diferentes perspectivas pero que, asimismo, son consecuencia de una manera de ejercer la profesión directamente identificada con la misión, visión y valores del centro. La cultura asistencial debería fluir de arriba hacia abajo con un lenguaje proactivo, reconociendo sin miramientos la innegable importancia del personal gerocultor y otorgándole el protagonismo que merece por ser la piedra clave de la atención geriátrica.

Para que el personal gerocultor lleve a buen término todas las funciones que tiene encomendadas, habida cuenta de las condiciones psicoafectivas que circunscriben su trabajo, deberíamos estar permanentemente vigilantes de su nivel de estrés y/o burnout (agotamiento emocional, despersonalización y baja realización personal). En un enfoque paralelo, el análisis de las circunstancias que envuelven al personal con buen rendimiento profesional, psicológico y emocional se convierte en una suerte de benchmarking productivo (engagement).

Algunos estudios concluyen que el personal gerocultor "forma parte de un colectivo de riesgo, posee altos niveles de estrés y presenta altas puntuaciones en las dimensiones que configuran el síndrome de burnout. En concreto, el hecho de tener que enfrentarse día a día a una situación que puede llegar a desbordar sus ánimos personales, y sus estrategias para hacer frente a la situación amenazante, configura en la organización un clima de estrés crónico que amedrenta el rendimiento físico, psicológico y social del trabajador" (Martínez et al., 2014: 42). En un marco como el descrito, el equilibrio laboral se presenta como requisito previo para que la atención se preste en términos de calidad de vida. En consecuencia, la organización juega un papel fundamental en el desarrollo y solución del burnout. Por esta razón, modelos como el desarrollado, enfocados desde la proactividad necesaria para ponderar en su justo valor la importancia del trabajo del personal gerocultor para ofrecer niveles de calidad de vida suficientemente dignos, ayudan a que este liderazgo asistencial pase del plano teórico al plano del reconocimiento explícito. Registrar los resultados de las supervisiones, analizar la distribución de no conformidades por categorías (graves, moderada y leve) y exponer las tendencias positivas que se suponen observables desde la implantación de modelos como Habitus, ayuda a mejorar la sensación de realización personal desde la valoración positiva del trabajo. El estilo de la organización, su preocupación por conseguir que el desempeño profesional se conciencie de la necesidad de atender conforme a la individualidad de cada persona y a la percepción doméstica del entorno sociofamiliar, determinará si la inercia emprendida es o no creíble. Un ideario sin datos no aporta nada; un sistema con registros detecta oportunidades de mejora que redundan en un incremento de la calidad asistencial.

Nuestro objetivo es generar unos hábitos profesionales que se abstraigan de los modelos de supervisión, esto es, que el personal gerocultor tenga tan interiorizada la buena praxis que esta no sea consecuencia de una evaluación, sino del modus operandi propio de la organización. Para lograrlo, el centro tendrá que demostrar que no hay dependencia entre el tipo de supervisión (presencial o deductiva) y el resultado obtenido en la evaluación. Este tipo de implementaciones incidiría directamente en la realización personal desde muy diversos factores. Cada trabajador/a, diariamente, podría percibir esa sensación de realización desde su interacción con las personas residentes y/o desde la valoración positiva y explícita de su valía profesional. Aplicando la pirámide de Maslow a los entornos laborales, podría afirmarse que aquellas organizaciones que despliegan estrategias de evaluación proactiva orientadas al bienestar psicoemocional de la personas residentes estimulan los mecanismos necesarios para alcanzar los tres niveles superiores: afiliación (relaciones interpersonales para sentirse parte de un grupo), reconocimiento (sentimiento de aceptación social para avanzar hacia la autorrealización) y autorrealización (búsqueda de un sentido a la vida). Nada de esto servirá si las encuestas de clima/satisfacción laboral refutan nuestras intenciones desde resultados que no acompañan el discurso.

Desde pruebas de independencia de chi cuadrado, el modelo analiza si la detección de no conformidades en categorías no relevantes (leve) es consecuencia de la presencia de el/la supervisor/a en el proceso de atención (hipótesis nula), para un nivel de confianza del $99,9 \%$ y un grado de libertad $\left(\chi^{2}=10,83\right)$. El valor alcanzado por la variable $\chi^{2}$ solo explica la dependencia/independencia entre ambos atributos (tipo de supervisión y detección o no de no conformidades leves) y no si los resultados de las evaluaciones avalan hábitos de trabajo excelentes. Si la concienciación profesional no solo aflora desde la presión vigilante sino que, sobre todo, es fruto de políticas organizativas que han implementado un modo de hacer garantista de las buenas praxis desde acciones formativas y canales de información 
apropiados, el registro de prácticas no adecuadas en las checklist correspondientes debería ser residual. La evaluación global del centro no vendría determinada por correlación alguna, sino por un simple índice que resumiera todas las incidencias documentadas en un periodo de análisis. El problema radicaría en la acotación de los intervalos que limitaran los niveles de calidad, aún más complejo porque cada categoría de la no conformidad presenta un peso específico concreto y porque el número de no conformidades detectado también dimensionaría las prácticas no adecuadas.

Supongamos que el factor de ponderación para cada nivel es respectivamente 3, 2 y 1 . Imaginemos, por un lado, un centro (A) de 100 plazas con 150 no conformidades distribuidas a razón de 85 graves, 40 moderadas y 25 leves; por otro lado, una residencia

(B) de 50 plazas con 10 graves, 15 moderadas y 175 leves para un total de 200 no conformidades.

- Intervalos de calidad y puntuación máxima tolerada:

$\left[\begin{array}{ll}1,00 \geq \mathrm{i}>0,80 & \rightarrow \text { Muy bueno } \\ 0,80 \geq \mathrm{i}>0,60 & \rightarrow \text { Bueno } \\ 0,60 \geq \mathrm{i}>0,40 & \rightarrow \text { Regular } \\ 0,40 \geq \mathrm{i}>0,20 & \rightarrow \text { Deficiente } \\ \mathrm{i} \leq 0,20 & \rightarrow \text { Muy deficiente }\end{array}\right.$ Centros A y B

Ambos centros no trabajan con el mismo número de subáreas críticas (15 en el centro A y 10 en el B), pero ya hemos demostrado la irrelevancia de este hecho si el binomio nivel de confianza-margen de error es diferente a 99\%-1\%. Antes de proceder a idear ningún sistema de acotación, deberíamos limitar la comisión de no conformidades a un porcentaje de tolerancia máxima (6\% según la Tabla 7). A continuación vamos a realizar los cálculos previos para construir dos modos diferentes de escalonar las buenas praxis.

\subsection{Acotación porcentual}

Acota los intervalos para la definición de niveles de calidad atendiendo a una misma amplitud (cociente entre uno y el número de intervalos) y con independencia del número de elementos que teóricamente pudieran contener:

(*) Según la expresión para el cálculo del tamaño de muestra (punto 4.2.), nueve es el número medio de supervisiones diarias para ambos centros.

- Índice de calidad (i): uno menos el cociente entre la suma de los productos de cada categoría de no conformidad por su correspondiente ponderación y el producto del número máximo de no conformidades por el valor de máxima ponderación:

$$
\begin{array}{ll}
\text { Centro } A \rightarrow 1-\left(85^{\star} 3+40^{\star} 2+25\right) /\left(197^{\star} 3\right)=0,390 & \rightarrow \text { Deficiente } \\
\text { Centro } B \rightarrow 1-\left(10^{\star} 3+15^{\star} 2+175\right) /\left(197^{\star} 3\right)=0,602 & \rightarrow \text { Bueno }
\end{array}
$$

$\begin{array}{ll}\text { nivel de confianza: } & 98 \% \\ \text { margen de error: } & 2 \% \\ \text { tamaño de muestra diaria }{ }^{(*)}: & 9 \\ \text { tolerancia máxima: } & 9 \times 365 \times 6 \%=197\end{array}$

Como se ve, el nivel de calidad depende en mayor medida de la frecuencia de cada categoría de consecuencia (leve, moderada o grave) que del valor absoluto del número de no conformidades detectado.

Trabajar con intervalos de una misma amplitud porcentual podría no corresponderse con un histograma de frecuencias que fuera más o menos constante. En otros términos, tendríamos que comprobar si la probabilidad teórica de pertenecer a uno u otro intervalo es similar. Empíricamente se demuestra que la concentración de valores en cada intervalo no es equiprobable. Si relacionamos todas las puntuaciones posibles para diferentes números de no conformidades ( $n$ ) y ponderaciones de las tres categorías de gravedad (número total de combinaciones igual a $V R_{3}^{n}=3^{n}$ ), y construimos los histogramas de frecuencias para cada caso simulado, observaremos una progresiva adaptación de las distribuciones de probabilidad a la campana de Gauss (coeficientes de asimetría nulos y curtosis descendentes y muy próximos a cero a medida que aumenta $n$ ). Analicemos si este hecho aconseja la asignación de niveles de calidad conforme a otro método alternativo.

Tabla 9. Aproximación a la curva normal de puntuaciones totales

\begin{tabular}{|r|r|c|c|c|c|}
\hline no NC (n) & Variaciones (3) & Curtosis & Asimetría & Media & Desviación \\
\hline 3 & 27 & $-0,347$ & 0,000 & 6,000 & 1,441 \\
\hline 4 & 81 & $-0,321$ & 0,000 & 8,000 & 1,643 \\
\hline 5 & 243 & $-0,281$ & 0,000 & 10,000 & 1,830 \\
\hline 6 & 729 & $-0,243$ & 0,000 & 12,000 & 2,001 \\
\hline 7 & 2.187 & $-0,212$ & 0,000 & 14,000 & 2,161 \\
\hline 8 & 6.561 & $-0,187$ & 0,000 & 16,000 & 2,310 \\
\hline 9 & 19.683 & $-0,166$ & 0,000 & 18,000 & 2,450 \\
\hline 10 & 59.049 & $-0,150$ & 0,000 & 20,000 & $\begin{array}{l}\text { A medida que incremente el número de no conformidades, la } \\
\text { distribución de frecuencias se normaliza con una media igual a } \\
\text { 2n y una desviación cada vez menor respecto del valor central } \\
\text { (concentración). }\end{array}$ \\
\hline
\end{tabular}

Fuente: Elaboración propia. 


\subsection{Acotación probabilística}

Acota los intervalos para la definición de niveles de calidad atendiendo a una misma amplitud (cociente entre el recorrido de la puntuación ponderada y el número de intervalos, cinco en nuestro caso) pero considerando que los mismos están compuestos por un número diferente de elementos, que siguen, como se demuestra, una función de distribución normal. ¿Por qué se acota el nivel de calidad en función del recorrido y no según una distribución alícuota de combinaciones posibles, es decir, acorde con niveles que contuvieran un mismo número de elementos o, en otros términos, que se diera una equiprobabilidad en la pertenencia a uno u otro nivel igual al $20 \%(100 \% / 5)$ ? Si fijáramos las cotas en función de un mismo contenido para cada intervalo, dada la altísima concentración de valores en torno a la media propia de una distribución normal, puntuaciones relativamente altas (frecuencias considerables en no conformidades moderadas y graves) podrían derivar en niveles de calidad buenos o, incluso, muy buenos. En un símil de evaluación académica, es como si valorásemos el conocimiento del alumnado en función del lugar que ocupa cada uno de ellos en una teórica función de distribución de sus calificaciones: siempre obtendríamos un mismo número de alumnos en cada nivel de evaluación (sobresaliente, notable, bien, suficiente e insuficiente). No parece ser un sistema adecuado para ponderar la diferencia entre la excelencia y los niveles inferiores de reconocimiento. En cualquier caso, en la Tabla 10 se comparan los resultados de ambas opciones.

La opción B favorece el logro de puntuaciones asociadas con niveles altos de calidad y, en consecuencia, podría sesgar la percepción verosímil de las buenas praxis. La opción A, por su parte, se aproxima a la escala porcentual pero presenta una mayor sensibilidad respecto de las posibles puntuaciones totales obtenibles. Esta última opción califica la praxis conforme a una misma amplitud lineal del intervalo, y pondera el nivel de calidad poniendo en valor el esfuerzo de la organización por alcanzar la excelencia.

Tabla 10. Acotación de niveles de calidad

\begin{tabular}{|c|c|c|c|c|}
\hline \multicolumn{2}{|l|}{ Opción A: acotación por recorrido } & \multicolumn{3}{|c|}{ Opción B: acotación por equiprobabilidad } \\
\hline Intervalos & Nivel de calidad & Probabilidad & Intervalos ${ }^{(*)}$ & Nivel de calidad \\
\hline $197 \leq \mathrm{pt} \leq 276$ & Muy bueno & $0 \% \leq p<20 \%$ & $197 \leq \mathrm{pt} \leq 377$ & Muy bueno \\
\hline $277 \leq \mathrm{pt} \leq 355$ & Bueno & $20 \% \leq p<40 \%$ & $378 \leq \mathrm{pt} \leq 389$ & Bueno \\
\hline $356 \leq \mathrm{pt} \leq 434$ & Regular & $40 \% \leq p<60 \%$ & $390 \leq \mathrm{pt} \leq 399$ & Regular \\
\hline $435 \leq p t \leq 513$ & Deficiente & $60 \% \leq p<80 \%$ & $400 \leq \mathrm{pt} \leq 411$ & Deficiente \\
\hline $514 \leq \mathrm{pt} \leq 591$ & Muy deficiente & $80 \% \leq p<100 \%$ & $411 \leq \mathrm{pt} \leq 591$ & Muy deficiente \\
\hline$\downarrow$ & $\nabla$ & $\nabla$ & & $\nabla$ \\
\hline $\begin{array}{l}\text { Centro A: } 360 \text { puntos (pt) } \\
\text { Nivel de calidad: regular }\end{array}$ & $\begin{array}{l}\text { Centro B: } 240 \text { puntos (pt) } \\
\text { Nivel de calidad: muy bueno }\end{array}$ & $\begin{array}{l}\text { Centro A: } 360 \text { puntos (pt } \\
\text { Nivel de calidad: muy bu }\end{array}$ & $\begin{array}{l}\text { Centro } \\
\text { Nivel c }\end{array}$ & $\begin{array}{l}240 \text { puntos (pt) } \\
\text { calidad: muy bueno }\end{array}$ \\
\hline
\end{tabular}

${ }^{(*}$ Valor que, para una distribución normal acumulada, deja a la izquierda de las cotas de cada intervalo un área igual al valor de las respectivas cotas de cada intervalo de probabilidad.

Fuente: Elaboración propia.

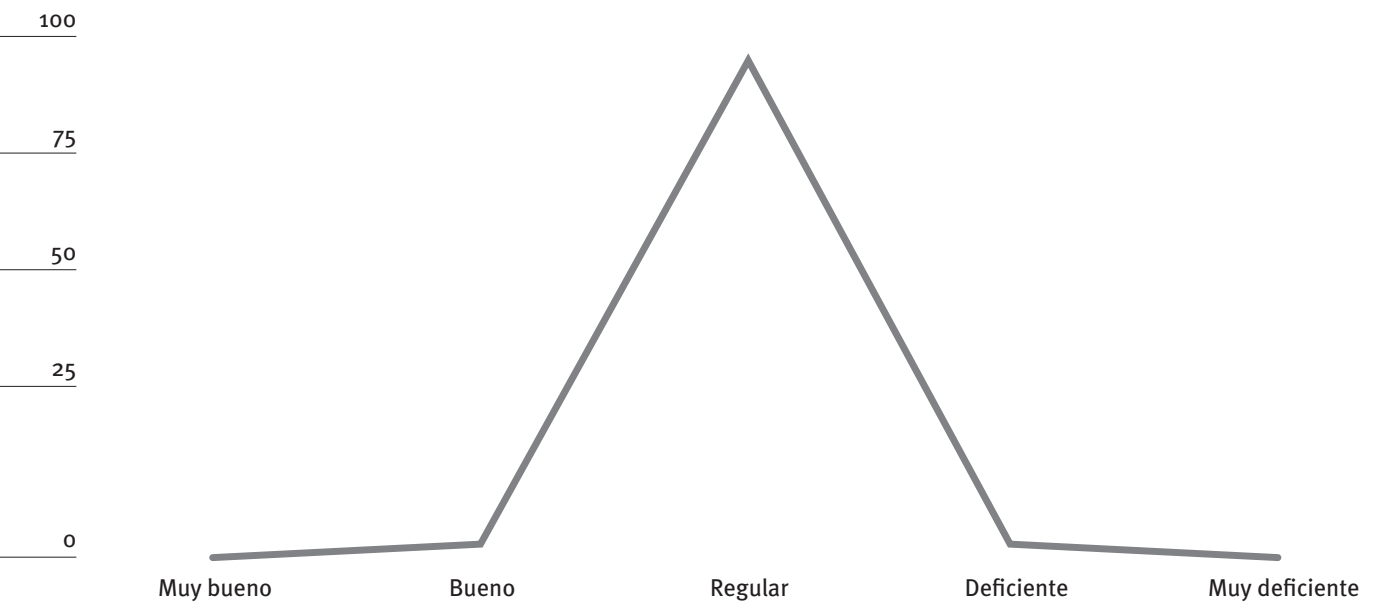

Fuente: Elaboración propia. 
Solo las organizaciones excelentes conseguirán niveles de calidad "muy buenos", porque la probabilidad de pertenencia al intervalo, a diferencia de la equiprobabilidad propuesta por la opción $B$, es baja. La gráfica muestra la concentración de puntuaciones totales por nivel de calidad para el ejemplo propuesto. Obsérvese que es prácticamente simétrica y que, a pesar de la presumiblemente bajísima posibilidad de optar al nivel excelente, el total de combinaciones posibles para acceder a dicho nivel es de $1,34 \times 10^{85}$ para el nivel de tolerancia de no conformidades admitido $(6 \%=197 \mathrm{NC})$.

Desde un enfoque público de evaluación de redes asistenciales, el uso de herramientas como Habitus vehiculiza la fijación de estándares de referencia y el diseño de mapas comparativos desde perspectivas intra (centros de una misma organización) o extra (organizaciones o centros de diferentes redes comarcales o autonómicas). Como detalla el siguiente punto, la homogeneización del cálculo de los indicadores utilizados es un proceso obligado si aspiramos a dotar de verosimilitud al sistema. Y, como la implantación de un modelo como el desarrollado no es aún requisito funcional de ninguna normativa, las Administraciones Públicas deberían poner en valor el esfuerzo derivado de la voluntad de querer contemplar cuantas áreas de atención son especialmente críticas desde la sensibilidad del entorno sociofamiliar. En los programas piloto a diseñar para llevar a la práctica este tipo de experiencias, el nivel de calidad de cada centro debería ser consecuentemente rectificado por la dimensión del esfuerzo (no es igual abordar tres o cuatro áreas críticas que una veintena). El indicador sintético definido adoptaría forma de percentil para ubicar las buenas praxis en el contexto de análisis.

\section{6. 'Benchmarking'}

Si por benchmarking entendemos todo aquel proceso de evaluación comparada del desempeño a partir del cual una organización busca calificar sus prácticas para mejorar las expectativas de sus clientes, la compartición de datos y resultados que supone es una inmejorable oportunidad para aprender con las mejores experiencias del sector. Una dinámica de benchmarking trata de imprimir fuerza en una misma dirección desde aquellos vectores que delimitan la complementariedad necesaria para el avance conjunto (aprendizaje mutuo y recíproco).

Figura 8. Facilitando el 'benchmarking'

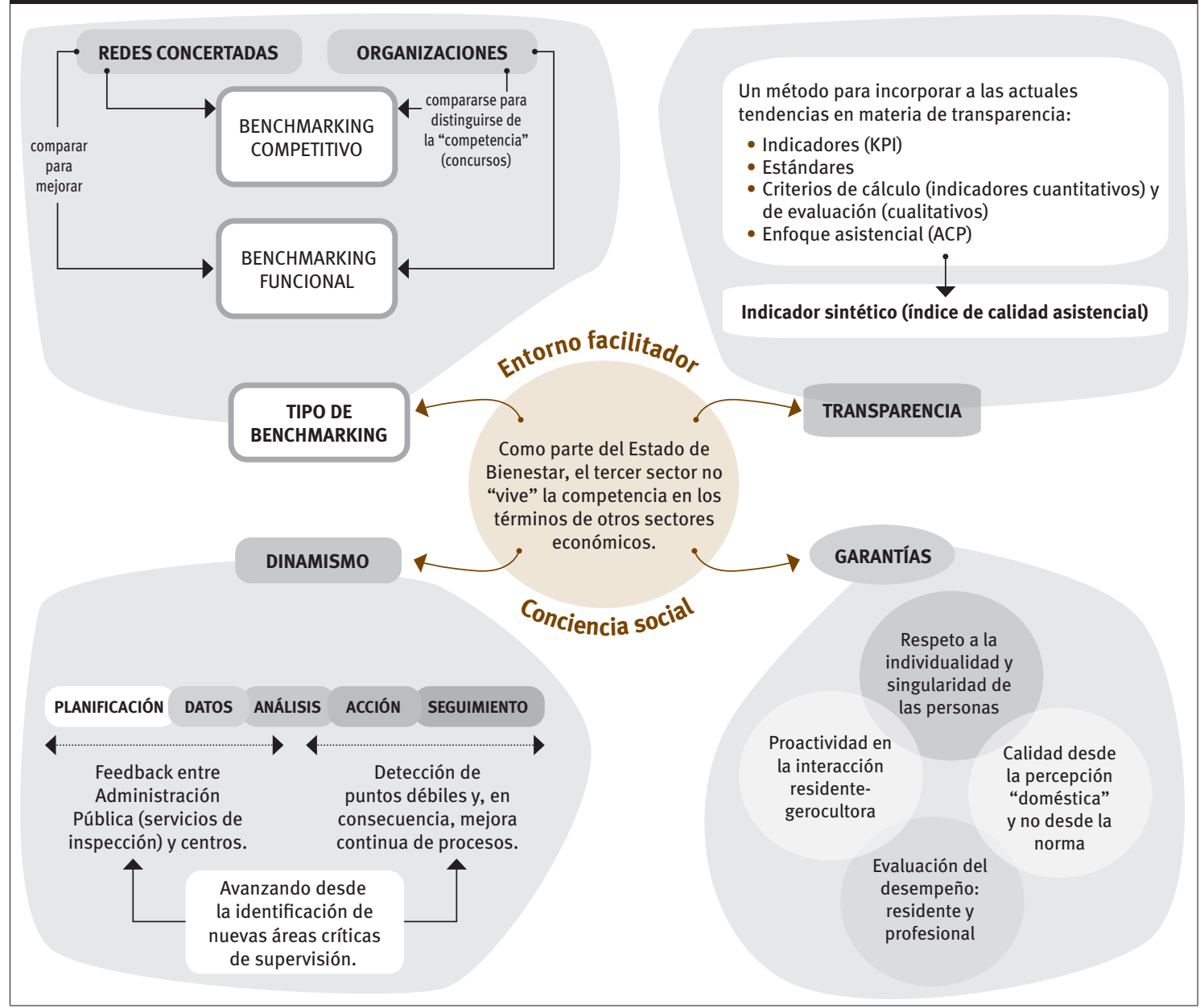


Los servicios sociales, como sector con identidad propia y diferenciada de otras que históricamente han procurado servicios a las personas más necesitadas, han adolecido de falta de perspectivas macro transversales para contrastar el avance de cada uno de los subsectores que lo integran. El progreso asistencial de las últimas décadas, indiscutible desde diferentes perspectivas, ha originado algunas comparativas impulsadas, en todo caso, desde el liderazgo de las disciplinas que han gobernado la atención a los colectivos más desfavorecidos. Los profesionales, públicos y privados, nos hemos erigido en líderes de la atención para legislar y organizar conforme a nuestras propias preocupaciones, unas veces desde las limitaciones presupuestarias y otras desde una supuesta garantía normativa en la que muchas veces no cabe la dimensión humana de la atención. Como consecuencia, el panorama estatal desemboca en un sistema de protección social divergente que da "soluciones" poco homogéneas a un mismo problema. Ante un escenario tan diverso, los ejecutivos autonómicos no se han preguntado si la dispersión es producto de la eficiencia de los modelos de atención, de la dotación presupuestaria al sistema social o de la innovación asistencial implementada. Mientras estas evoluciones desarmonizadas no se investiguen las diferencias seguirán existiendo y, así como la brecha salarial por razón de género es una lacra social, la brecha asistencial por razón de padrón sería una desigualdad a un mismo nivel de importancia social. Pero la equiparación ha de lograrse por aproximación a los mejores, en todos los sentidos, y no por la limitación del avance de unos sobre los demás.

Una regla fundamental en el diseño de comparadores (benchs) es que el indicador (KPI) sea obligatoriamente homogéneo. Esta pretendida uniformidad no pasa exclusivamente por expresar su cálculo de una única manera, con arreglo a idénticos criterios, sino, ante todo, por rectificar el valor obtenido por efecto del contexto de aplicación. ¿El número medio de caídas por residente, cociente entre el total de caídas registradas en un periodo y el número medio de residentes en el mismo, es independiente del índice de case-mix del centro o de la implementación de medidas de eliminación de sujeciones? Evidentemente, no. Las condiciones circunstanciales de la atención deben parametrizar, asimismo, el valor del comparador para dotarlo de la homogeneidad necesaria para el contraste.

Insistiremos nuevamente en la inevitable distinción entre benchmarking público y benchmarking sociofamiliar, entre la necesaria inspección administrativa para evaluar las garantías asistenciales de los centros desde indicadores de proceso y resultado (se valora el resultado agregado y no la intervención personalizada) y la no menos imprescindible supervisión de la calidad asistencial desde los ojos del entorno más íntimo de las personas residentes. Una y otra, sobre indicadores de proceso o de resultado, deberían converger en la apreciación cualitativa de la calidad. Son, en definitiva, dos caminos que nos llevarían a un mismo destino pero cada cual transitando por su vereda. Complementando el enfoque evaluador público desde claves alternativas basadas en los modelos de calidad de vida y atención centrada en la persona, alcanzaremos nuevas cotas interpretativas de la calidad, de modo que la misma no sea entendida como algo que transciende el sentir de los clientes para convertirse en un medio que, por ajustarse al estricto cumplimiento de la norma, desatiende los aspectos emocionales de la atención, en última instancia aquellas parcelas verdaderamente importantes para quienes decidimos ingresar a nuestros seres queridos en un centro residencial.

En un entorno asistencial en el que la Administración Pública verdaderamente enarbolase la bandera de la participación de las familias en el tipo de atención que quieren recibir, más allá de la mera cumplimentación de una encuesta de satisfacción, la implementación de este tipo modelos de supervisión acompañaría con pruebas la certeza de sus intenciones. Además, la implementación de dinámicas de benchmarking nos ayudará a comparar nuestra capacidad como organizaciones al servicio de las personas mayores (benchmarking competitivo aplicable en procesos de adjudicación de gestión indirecta de recursos). Igualmente, en un sector altamente atomizado porque la demanda está básicamente focalizada en la proximidad geográfica, trabajar desde la compartición del conocimiento nos facilitará la identificación de las mejores prácticas para que estas rutinas excelentes puedan ser replicadas en otros centros porque, precisamente, no se constituyen en competidores que comparten un mismo mercado (benchmarking funcional).

\section{Etapas en la implementación del método}

Implementar una herramienta como Habitus no es la simple instalación de un software que permita su operatividad. El modelo presentado pretende ser una filosofía de trabajo basada en evaluaciones proactivas que gradualmente van barnizando la atención desde las buenas prácticas como impulso de la mejora continua. No se aconseja la implantación de esta metodología si la inmediatez en la obtención de resultados es nuestro objetivo, aquello de parecer más que ser. El método desarrollado solo desembocará en el arraigo de una cultura asistencial, que busca cubrir las expectativas de las personas residentes y/o su entrono sociofamiliar, si la organización -concretamente, quienes la dirigen - se plantea su implementación como una sucesión de etapas a las que no accederemos sin terminar ni evaluar cada fase previa.

Con la disponibilidad propia de cada organización, iremos consolidando un modelo de entender la calidad diferenciado y complementario de lo que habitualmente se interpreta como tal. Añadiremos 


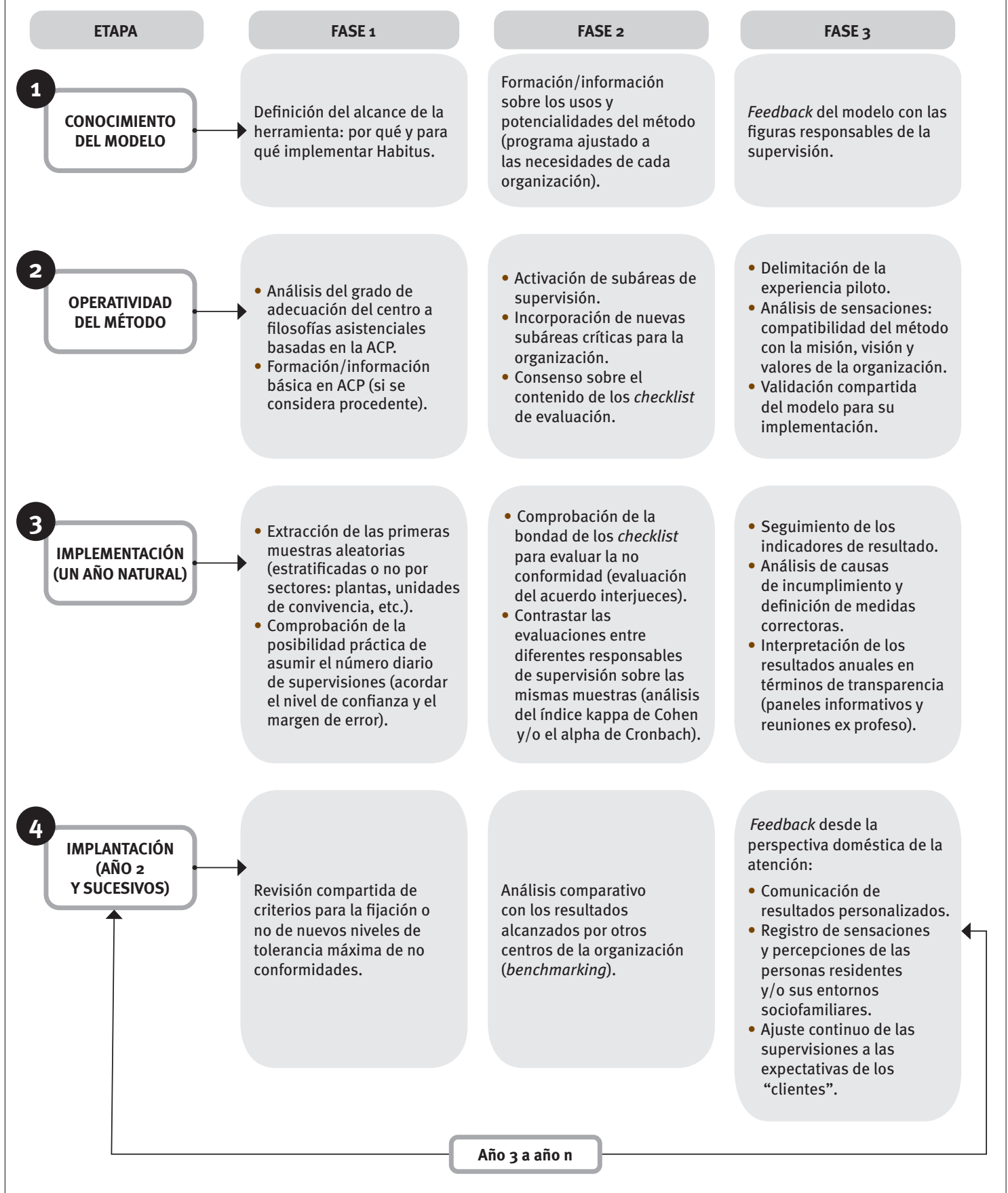

Fuente: Elaboración propia.

los beneficios de la norma informal al cumplimiento de la norma formal para cerrar el círculo de la calidad, en un ejercicio de puesta en práctica de un sistema teórico que debe contar, obligatoriamente, con los principales agentes que interactúan en la atención residencial a personas mayores (residentes $\mathrm{y} / \mathrm{o}$ entorno sociofamiliar, centros gestores y profesionales). El objetivo es claro: contagiar el afán no solo por hacerlo bien sino, sobre todo, por sentirnos bien en nuestro desempeño profesional, por hacer de nuestra vocación de servicio un valor distintivo de nuestra organización.

\section{Conclusiones}

De todo lo expuesto se pueden extraer una serie de conclusiones:

- Los modelos asistenciales basados en corrientes de pensamiento como la psicología humanista han venido para quedarse. De alguna manera, son la siguiente etapa en la evolución de los servicios residenciales para persona mayores: beneficencia $\rightarrow$ profesionalización (beneficiencia) $\rightarrow$ dimensión humana de la atención. 
- Las actuales herramientas de gestión residencial no contemplan, en la mayoría de los casos, el registro, análisis y explotación de datos para mostrar una preocupación latente por mejorar la atención desde parámetros asistenciales alternativos y esenciales, pero no por ello contrarios a aquellos que la fase de profesionalización ha considerado imprescindibles y nucleares. Un método como Habitus es una herramienta dinámica que evoluciona con los centros, que se nutre de sus experiencias para producir un feedback con el entorno sociofamiliar que evidencie la preocupación de la organización por atender conforme a la sensibilidad de aquel: perder requisitos improductivos desde la óptica social para ganar en humanidad.

- La humanización de la atención es escuchar activamente la voz de las personas residentes y/o su entorno familiar para procurar que la "hogarización" de los centros residenciales no se quede en una mera declaración de intenciones. Es necesario avanzar en la definición de indicadores que integren el bienestar psicoemocional como un eje fundamental en la atención residencial a nuestras y nuestros mayores. No se defiende en dimensión alguna la suplantación de otros roles asistenciales sino la complementación de disciplinas y el aprovechamiento de sus sinergias.

- El panorama estatal es claramente ex ante en una evaluación de los servicios que no busca tanto la continuidad de las buenas praxis como aprobar los exámenes que suponen las auditorías de cualquier índole. El cumplimiento de la norma es el estandarte más visible del proceso de acreditación de la calidad, convirtiendo el método en algo más correctivo que preventivo y generalmente poco transparente para el conocimiento público de los resultados obtenidos. En una actividad socialmente tan sensible como la nuestra, la implementación de modelos garantistas del buen hacer diario debería ser una condición y no un valor añadido. $Y$ en este sentido se ofrece el modelo: Habitus en una alternativa evaluativa que complementa la valoración pública de los centros desde la necesaria e indisociable colaboración públicoprivada en la atención residencial a personas mayores. En definitiva, pretende constituirse en un potenciador de la sinergia entre agentes para promover el avance conjunto del sector.

- Empeñarse en separar gestión y perspectiva humanista es un posicionamiento que obstaculiza la interconexión necesaria entre diferentes disciplinas para un avance conjunto de la atención. Entender que son vasos comunicantes, y que no es aconsejable romper el equilibrio entre uno y otro para que prevalezca una de las dos mitades, es un principio irrenunciable del modelo. Humanizar sin gestionar es como gestionar sin humanizar, un claro ejemplo de entender la atención desde la perspectiva de una disciplina dominante; gestionar para humanizar es sistematizar, medir, evaluar y corregir desde la evidencia para mejorar la calidad de atención, un modo de concebir la prestación del servicio desde códigos éticos.

- El uso de un lenguaje proactivo (no conformidades y oportunidades de mejora frente a malas praxis y errores en el ejercicio profesional) facilita la implementación de sistemas de evaluación alejados de connotaciones disciplinarias. De la amenaza de la sanción se pasa a depositar la confianza en el buen quehacer profesional de las plantillas porque hemos canalizado las medidas oportunas para conseguirlo.

- El personal gerocultor es el epicentro de la atención. Reconocerlo es tanto un gesto de humildad como una declaración firme para entender que es este colectivo profesional, y no ningún otro, quien se erige en figura de referencia inmediata para las personas residentes $y / 0$ su entorno sociofamiliar. La imagen de la residencia se proyecta desde estas figuras de igual modo que son primeras receptoras de las reclamaciones verbales o informales de familias y entornos sociales. Sin lugar a dudas, son las bisagras que conectan dos planos simétricos inseparables: necesidad de atención y estilo de servicio.

- Una gestión de éxito para por el tamiz de la eficiencia. En consecuencia, el modelo hará uso de cuantas técnicas analíticas (inferencia estadística), modelos de interpretación y soportes digitales (bases de datos y registros táctiles) se entiendan necesarios para cumplir con las expectativas de los clientes (residentes, entorno sociofamiliar y/o Administraciones Públicas) desde la racionalización de recursos. Nuestro objetivo es claro: atender como nos gustaría ser atendidos. Para pasar del ánimo al cometido aplicaremos tanto métodos basados en las propias experiencias como prácticas compartidas por otras organizaciones en dinámicas de benchmarking.

- La objetivación de la categoría de la consecuencia potencial de las no conformidades en el estado de salud y/o equilibrio psicoemocional (leve, moderado o grave) es el eje central del modelo. Ponderar la no conformidad permite validar la eficacia de las acciones implementadas para reconducir el nivel de calidad desde la perspectiva doméstica. Todo un conjunto de gráficos, listados e indicadores se modulan en un software que ayuda a la toma de decisiones desde la interpretación de los resultados obtenidos. Desde el análisis de los incumplimientos observados podremos determinar si la solución pasa por diseñar planes de formación específicas, abrir campañas de información para sensibilizar la concienciación profesional y/o reorganizar la atención directa conforme a criterios asistenciales alternativos.

- Fomentar la transparencia de procesos y resultados como fortalezas de la organización y, por proyección, de un sector que no debería ser 
analizado desde las reglas de la competencia tradicional dado su carácter localista y atomizado, debería ser una iniciativa igualmente compartida desde las administraciones públicas. Incorporar las enseñanzas de diferentes herramientas para la mejora continua (filosofía Kaizen, por ejemplo), adaptadas a las características de la actividad geriátrica, revertiría positivamente en el avance conjunto de las redes residenciales. Esta actitud para facilitar la compartición de experiencias y promover la transparencia para la mejora tiene un modo de hacer: benchmarking.

\section{Epílogo}

La excepcionalidad de un confinamiento tan obligado como solidario por causa de la COVID-19 ha condicionado la composición de un documento que quiere defender más que nunca la inexcusable adaptación del centro residencial a la familia. La idea, el sentido finalmente buscado, ha evolucionado conforme han ido sucediéndose las noticias acerca de un virus especialmente virulento con las personas mayores. Ahora, incluso con mayor vehemencia, defiendo que los nuevos tiempos deben exigir la apertura de los centros a la participación del entorno sociofamiliar. Su visibilidad y protagonismo como engarce con las personas residentes no puede, ni debe, quedar en una mera declaración política más o menos creíble.

Ante escenarios tan dantescos como los recientemente vividos, ni Administraciones Públicas ni centros gestores deberían seguir obstinadamente empeñados en el cuidado desde principios anclados en modelos anquilosados por normativas más preocupadas de la forma que del fondo, por inspecciones públicas convencidas de que el éxito en la atención tiene más de cumplimiento de requisitos legales y funcionales que de interactuación con las personas usuarias y/o su círculo íntimo. Cuando nos golpea una realidad tan dolorosa que obliga a dictar resoluciones para limitar el acceso exclusivamente al personal y a los proveedores bajo las más estrictas medidas de control, el entorno sociofamiliar vive su impotencia desde la soledad más desgarradora. Todo cuanto podamos imaginar para diseñar alternativas operativas que favorezcan un cambio de paradigma, que apoye sin dobleces la sensación de hogar, debería ser el eje sobre el que fundamentar futuros modelos de atención desde la dimensión humana, a veces olvidada conscientemente, equivocadamente, y otras desoída porque solo los profesionales sabemos qué necesitan las personas residentes y su entorno familiar para alcanzar el bienestar. 


\section{Referencias bibliográficas}

AUREN (2019): DENAdat, una herramienta para el dimensionamiento de plantillas de auxiliares de geriatría, 〈http://www.denadat.com〉.

CALVO, F. (1990): Estadística aplicada, Ediciones Deusto.

FIGUEROA, J. (2017): Diseño de investigación y análisis de datos, Universidad de Almería.

FRÍAS-NAVARRO, D. (2019): Apuntes de consistencia interna de las puntuaciones de un instrumento de medida, Universidad de Valencia.

GIL GREGORIO, P.; LÓPEZ TRIGO, J.A. y GÓMEZ MARTíN, M.P. (coords.) (2013): Manual de buena práctica en cuidado a personas mayores, Madrid, Sociedad Española de Geriatría y Gerontología.

GOBIERNO VASCO (2019): Decreto 126/2019, de 30 de julio, de centros residenciales para personas mayores en el ámbito de la Comunidad Autónoma del País Vasco", Boletín Oficial del País Vasco, no 170, 9-9-2019, <https:// www.euskadi.eus/y22-bopv/es/bopv2/ datos/2019/09/1904108a.shtmls.

GÓMEZ MARTÍN, M.P. y DÍAZ VEGA, P. (coords.) (2011): Guía práctica para favorecer el buen trato a las personas mayores, Sociedad Española de Geriatría y Gerontología.

GONZÁLEZ BOLEA, L.; CARMONA CALVO M.A.; y RIVAS ZAPATA, M.A. (2017): Guía para la medición directa de la satisfacción de los clientes, Instituto Andaluz de Tecnología.

GONZALEZ CARREÑO, A. (2013): Intervención en calidad de vida de personas mayores en la residencia San Sebastián.

GÓMEZ ORDOKI, A. (2017): MORETAG: Modelo referencial de asignación de tiempos de auxiliar de geriatría, Lares Euskadi (http://www.lareseuskadi.org/ uploads/media/MORETAG-Lares_Euskadi.pdf).
INFAIMON (2018): “Control de calidad empresas: el camino hacia la máxima eficiencia", 6 de febrero, 〈https://blog.infaimon.com/control-de-calidadempresas-camino-maxima-eficiencia/>.

KNAPP M. (1988), La economía de los servicios sociales, La Llar del Libre.

LÓPEZ DE ULLIBARRI GALPARSORO, I. y PITA FERNÁNDEZ, S. (2001): Medidas de concordancia: el índice de Kappa. Unidad de Epidemiología Clínica y Bioestadística, Complexo HospitalarioUniversitario Juan Canalejo.

MARTÍNEZ, J.P. et al. (2014): "Burnout en cuidadores profesionales y calidad de vida en residentes de centros institucionalizados", European Journal of Investigation in Health, Psychology and Education, vol. 4, no 1, pp. 41-53, 〈https:// doi.org/10.1989/ejihpe.v4i1.39>.

MARTÍNEZ RODRÍGUEZ, T. (2013): Avanzar en AGCPInstrumento para la revisión participativaCuestionario Residencias.

- (2016): "Auxiliares y gerocultores/as, profesionales clave en la ACP", http://acpgerontologia.blogspot. com/2016/11/auxiliares-y-gerocultoresas.html.

- (coord.) (2016): Respetando la intimidad: protección y trato cálido. Recomendaciones para la buena praxis en servicios sociales, serie Ética y Servicios Sociales, $\mathrm{n}$ ㅇ 2, Oviedo, Consejería de Derechos y Servicios Sociales del Principado de Asturias.

- (2017): “Hasta ahora los cuidados se han concebido ignorando lo que cada persona siente y piensa", Mayor Actual, 29 de octubre, <http:// www.lacasademitia.es/articulo/sociedad/ teresa-mart/20171121052315074297.html>.

MINISTERIO DE TRABAJO, MIGRACIONES Y SEGURIDAD SOCIAL (2018): Resolución de 11 de septiembre 
de 2018, de la Dirección General de Trabajo, por la que se registra y publica el VII Convenio colectivo marco estatal de servicios de atención a las personas dependientes y desarrollo de la promoción de la autonomía personal (residencias privadas de personas mayores y del servicio de ayuda a domicilio)" Boletín Oficial del Estado, n- 229, 21-9-2018, pp. 91.393-91.457, 〈https://www.boe.es/eli/es/ res/2018/09/11/(3)>.

NAVARRO, L.F. (coord.) (2019): Protocolos para el cuidado básico de personas mayores: sistema de acreditación de servicios sociales, Sociedad Española de Geriatría y Gerontología.

TRINIDAD, D.J. (coord.) (2007): Protocolos asistenciales en residencias de mayores, Madrid, Servicio Regional de Bienestar Social de la Comunidad de Madrid.

VARIOS AUTORES (2002): Manual del proceso de lavandería en centros residenciales para personas mayores, Consejería de Servicios Sociales, Comunidad de Madrid.
- (2004): Guía de higiene integral en residencias de personas mayores, Consejería de Sanidad y Consumo, Comunidad de Madrid.

- (2010): Protocolos de actuación. Residencia de personas mayores, Servicio Foral Residencial, Diputación Foral de Bizkaia.

- (2011): Cómo se eliminan las sujeciones. Guía para la eliminación de sujeciones físicas y químicas en centros de atención sociosanitaria y domicilios (Norma Libera-Ger), Fundación Cuidados Dignos.

- (2014): Burnout en cuidadores profesionales y calidad de vida en residentes de centros institucionalizados, Sociedad Española de Geriatría y Gerontología.

- (2014): Documento de Consenso sobre Sujeciones Mecánicas y Farmacológicas, Sociedad Española de Geriatría y Gerontología.

- (2020): Escala LIBE (listado de indicadores de bienestar), Matia Instituto. 